\title{
Avaliação da importância relativa dos critérios para a seleção de Sistemas Integrados de Gestão (ERP) para uso em empresas da construção civil
}

\section{Evaluation of the importance of criteria for the selection of Integrated Management Systems (ERP) for use in civil construction companies}

\author{
Mirian Picinini Picinini Méxas ${ }^{1}$ \\ Helder Gomes Costa ${ }^{1}$ \\ Osvaldo Luiz Gonçalves Quelhas
}

\begin{abstract}
Resumo: A adoção de Sistemas Integrados de Gestão, também denotados sistemas ERP (Enterprise Resource Planning), introduziu a necessidade de se discutir o processo de avaliação deste tipo de sistemas, o qual está inserido em um contexto de múltiplas percepções ou critérios de avaliação. No presente trabalho, efetua-se uma revisão bibliográfica sistematizada em um conjunto de artigos publicados em periódicos indexados nas bases Scopus, ISI Web of Science ou Engineering Village, os quais relatam a construção/aplicação de modelos multicritério para avaliação de sistemas ERP. Com base nesta revisão bibliográfica, foi construído um conjunto de critérios e subcritérios, o qual foi submetido à validação por um conjunto de especialistas com experiência na seleção e implantação de ERP, resultando em uma árvore composta por 45 subcritérios agrupados em cinco critérios. Posteriormente, foi desenvolvida uma pesquisa de campo, da qual participaram 79 respondentes, principalmente das áreas de TI e Construção Civil, para captar percepções quanto à importância relativa destes critérios. A pesquisa revelou que os respondentes consideram os critérios Financeiro, Negócio e Software os mais importantes.
\end{abstract}

Palavras-chave: Sistema de informação. ERP. Construção civil. Multicritério. AHP. Fuzzy.

\begin{abstract}
The adoption of ERP (Enterprise Resource Planning) by companies has introduced the need of evaluating and selecting such systems. This discussion is embedded in a context of multiple perceptions or evaluation criteria. In the present study, it a systematic literature review was conducted on a set of papers published in journals indexed by Scopus, ISI Web of Science, and Engineering Village databases focusing on the multiple criteria evaluation of ERP systems. Based on this literature review, criteria and sub-criteria was set, which was submitted for validation by a group of professionals with strong ERP System selection and implementation experience resulting in a tree comprised of 45 sub-criteria grouped into five criteria. A survey of IT and civil construction areas was conducted on a sample of 79 respondents in order to investigate the relative importance of these criteria. The survey demonstrated that the Financial, Business, and Software criteria were considered by the respondents as the most important.
\end{abstract}

Keywords: Information system. ERP. Civil construction. Multicriteria. AHP. Fuzzy.

\section{Introdução}

A tendência, principalmente das grandes organizações, em utilizar aplicativos ou sistemas integrados é reportada em Laudon e Laudon (2007), que destaca que estes sistemas abrangem diversas áreas funcionais, executando processos de negócios que transpassam toda a organização. A característica dos sistemas integrados de gestão é também destacada por Stair (1998), que afirma que, apesar de os sistemas de informação terem surgido sem a preocupação com integração de dados, evoluíram e resultaram na incorporação da integração de dados como parte das estratégias organizacionais.
Neste âmbito, há uma tendência de as empresas utilizarem sistemas ERP (Enterprise Resource Planning), surgindo a necessidade de seleção e aquisição de alternativas entre as existentes no mercado. Geralmente, para se fazer esta seleção, são levados em consideração diferentes tipos de critérios, sendo alguns deles subjetivos.

Esta situação ocorre em diferentes setores de produção, sendo agravada no caso da indústria da Construção Civil pela complexidade de interligação de projetos neste setor. Segundo Marcondes (2007), a indústria da Construção Civil, se comparada às demais

\footnotetext{
Escola de Engenharia, Universidade Federal Fluminense - UFF, Rua Passos da Pátria, 156, Bloco D, Niterói, RJ, Brasil, e-mail: hgc@latec.uff.br; mirian_mexas@vm.uff.br; quelhas@latec.uff.br
} 
indústrias, possui características bastante peculiares. Apresenta-se como um setor muito heterogêneo e possui uma grande diversidade de especialidades, e, por vezes, com uma imensa disparidade em relação ao porte das empresas que a constituem, tornando assim mais complexa a integração de seus sistemas.

$\mathrm{Na}$ literatura, há diversos registros de modelagens multicritério para a seleção de sistemas ERP. No entanto, estes artigos encontram-se dispersos em diferentes veículos de publicação, o que dificulta uma visão global do problema.

O presente trabalho tem como objetivo captar a percepção de especialistas a respeito da importância dos critérios e subcritérios para a seleção de sistemas ERP, no contexto de empresas da indústria da Construção Civil.

Para que este objetivo fosse alcançado, foi aplicado um instrumento de coleta de dados: um questionário elaborado a partir de uma proposta de critérios baseada na revisão bibliográfica de textos que lidaram com a modelagem multicritério do problema de seleção de sistemas ERP. Os dados coletados na pesquisa foram tratados por meio de estatística descritiva e também apresentados graficamente.

Além desta introdução, este artigo é composto pela: seção 2, na qual se descreve o conceito sobre sistemas integrados de gestão (ERP); seção 3, na qual se apresenta o método de pesquisa aplicado neste trabalho; seção 4, que reporta uma síntese da revisão bibliográfica; seção 5 , que propõe o conjunto de critérios para a seleção de sistema ERP, representada por uma árvore ou estrutura de critérios e subcritérios, e de uma tabela com as descrições detalhadas de cada subcritério do nível mais baixo da hierarquia; seção 6 , que apresenta o mapeamento da percepção de importância dos critérios e subcritérios propostos, por meio da pesquisa de campo, na qual foi aplicado um questionário com um total de 79 respondentes. Foi realizada a análise dos resultados desses 79 respondentes, assim como de um subconjunto de 32 respondentes que implementaram sistemas ERP ou interfaces e, a seguir, foi realizada uma análise comparativa dos resultados desses dois grupos; e finalmente, na seção 7, é apresentada a conclusão da pesquisa.

\section{Considerações sobre sistemas ERP}

De acordo com Shi e Halpin (2003), um ERP provê um ambiente geral de trabalho para uma empresa integrar suas funções principais de gerenciamento de negócios em um banco de dados comum. Deste modo, as informações podem ser compartilhadas e a comunicação eficiente pode ser alcançada entre as funções de gestão. Para Goh (2006), os sistemas ERP estão no cerne das funções de negócio da empresa e, portanto, sua compreensão é fundamental. Eles podem servir três principais objetivos dentro da organização: operacional, tático e estratégico.

Vlachopoulou e Manthou (2006) consideram que a integração tem sido um desafio há muitos anos. Definem os ERPs como sistemas para toda a empresa, que automatizam todos os processos de negócio e substituem os sistemas legados, integrando todos os departamentos e funções de uma empresa em um único sistema, que roda em um banco de dados comum, facilitando o compartilhamento de informações e a comunicação entre os departamentos.

Para Choudhury (2009), um sistema ERP é um conjunto de pacotes de software de negócios que integra uma série de aplicações de software modular para atender a todas as funções de uma empresa.

Existem, atualmente, duas definições sobre sistemas ERPs: ERP proprietário ou P-ERP (Proprietary ERP) e ERP Livre de Código Aberto (FOS-ERP, do inglês Free Open Source-ERP). De acordo com Carvalho e Campos (2009), quando empresas usuárias compram licenças de ERP da empresa que os desenvolveu e tem a propriedade do software, chama-se ERP proprietário ou P-ERP. Também segundo esses autores, nos últimos anos surgiram os sistemas ERP Livres de Código Aberto (FOS-ERP), que são softwares que podem ser livremente distribuídos ou vendidos e que dá ao usuário a liberdade de executar o programa para qualquer propósito. Vale a pena ressaltar que, segundo Carvalho e Johansson (2010), a melhor opção para o futuro do FOS-ERP será o modelo de negócio SaaS (Software as a Service), ou seja, a aplicação em si é executada remotamente e fica hospedada nas máquinas do fabricante do software ou de parceiros, configuração esta que não é novidade no mundo dos ERP.

A pesquisa aqui realizada considera a seleção tanto de sistemas proprietários quanto de código aberto.

\section{Método de pesquisa}

Para a realização da pesquisa foram efetuadas as seguintes etapas:

- Revisão da literatura que se refere ao levantamento do estado da arte no contexto do problema, no qual foram examinados os referenciais teóricos sobre os temas da pesquisa que servirão como base para a proposta da modelagem de critérios;

- Com base no conhecimento obtido a partir da revisão da literatura, elaborou-se uma compilação de critérios e subcritérios pesquisados em trabalhos prévios, referentes à seleção de sistemas ERP que utilizaram o método multicritério AHP (Analytic Hierarchic Process) ou a metodologia Fuzzy. Esta relação de critérios e subcritérios foi agrupada por critérios e subcritérios afins, 
em uma árvore de critérios, composta por 49 subcritérios, os quais foram agregados em cinco critérios (Financeiro, Negócio, Software, Tecnológico e Fornecedor);

- Submissão da proposta inicial de árvore de critérios à validação por um grupo de Especialistas de TI - Tecnologia da Informação ("grupo focal"), selecionados por sua grande experiência em seleção de sistemas de informação gerenciais. No processo de validação, foram inicialmente realizadas entrevistas individuais com os especialistas; os resultados destas entrevistas foram compilados e enviados por e-mail aos especialistas entrevistados, obtendo-se o consenso entre os especialistas quanto à estrutura de critérios e subcritérios, além de suas respectivas definições. A árvore de critérios ilustrada na Figura 1 apresenta a estrutura de critérios e subcritérios obtida após a validação junto aos especialistas;

- Preparação e envio do questionário na ferramenta encuestafacil.com para diferentes grupos (TI, Construção Civil, Educação e Outros), no qual foi informado que a atribuição de pesos aos critérios teria que ter somatório igual a 100. Antes de ser enviado, o questionário foi testado e validado por especialistas experientes em seleção de sistemas ERP, com o objetivo de garantir o bom resultado da pesquisa; e

- Apresentação dos resultados do questionário por meio de duas amostras de dados: um grupo de 79 respondentes e um subconjunto de 32 respondentes que implementaram sistemas ERP ou interfaces. Os dados coletados foram apresentados por meio de estatística descritiva e da análise comparativa dos gráficos gerados.

\section{Síntese da revisão bibliográfica}

Inicialmente, para o desenvolvimento deste trabalho, foi feita uma pesquisa na literatura para mapear e selecionar modelos multicritério para a seleção de sistemas ERP. Esta pesquisa foi realizada nas bases SCOPUS, ISI (Web of Knowledge) $e$ Engineering Village, acessadas por meio do portal de periódicos da CAPES. A escolha deste recorte segue a argumentação apresentada em Rodriguez, Costa e Do Carmo (2013), que justifica o foco em uma revisão bibliográfica sistematizada em periódicos científicos pelo fato de que tais veículos são geralmente utilizados por acadêmicos e profissionais para disseminar novos resultados, o que corrobora para um maior nível de investigação, como destacado em Nord e Nord (1995), Ngai e Wat (2002), Van Raan (2003), Ngai, Xiu e Chau (2009) e Tavares Neto e Godinho Filho (2013). As palavras-chave inicialmente utilizadas para o desenvolvimento da pesquisa foram: "criteria for software selection", "software evaluation", "software system evaluation". Os registros encontrados foram analisados, tendo sido selecionados 16 artigos que utilizavam multicritério para a seleção de sistemas ERP, sendo que oito utilizaram o método AHP (Analytic Hierarchic Process) e oito utilizaram uma abordagem Fuzzy. Não foram encontrados artigos que utilizassem os métodos ELECTRE, Promethée, Topsis, Visa, Thor, Todim ou MacBeth.

Os artigos selecionados foram analisados, objetivando obter uma compilação dos critérios e subcritérios adotados nesses 16 artigos pesquisados, separando-os em cinco tabelas, organizados por grupo de critérios. Nestas tabelas, os artigos codificados como A1, A2, A3, A4, A5, A6, A7 e A8 referem-se

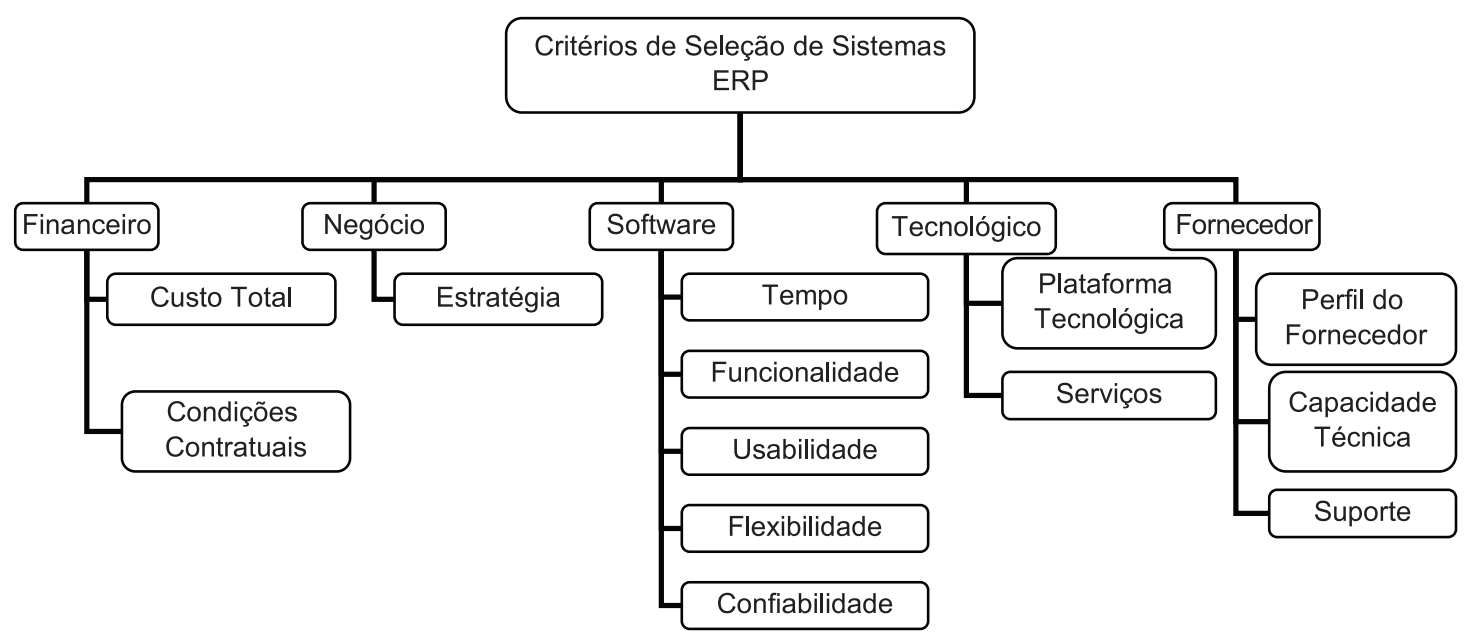

Figura 1. Árvore de critérios e subcritérios para seleção de sistemas ERP. 
a artigos baseados no AHP, já os artigos codificados como F1, F2, F3, F4, F5, F6, F7 e F8 referem-se a artigos que utilizaram uma abordagem Fuzzy. A seguinte legenda permite identificar os artigos codificados nas tabelas: A1 = Byun e Suh (1996); A2 = Kim e Moon (1997); A3 = Teltumbde (2000); A4 = Wei, Chien e Wang (2005); A5 = Natalia et al. (2006); A6 = Ayag e Ozdemir (2007); A7 = Lee, Lee e Park (2009); A8 = Yazgan, Boran e Goztepe (2009), F1 = Erol e Ferrell Junior (2003); F2 = Wei e Wang (2004); F3 = Lin, Hsu e Sheen (2007); F4 = Buyukozkan e Ruan (2008); F5=Bueno e Salmeron (2008); F6 = Ghapanchi, Jafarzadeh e Khakbaz (2008) ; F7 = Şen et al. (2009); F8 = Şen e Baraçli (2010).

A Tabela 1 apresenta os resultados referentes ao grupo de critérios denotado por: Financeiro. Ao se analisar os dados reportados na Tabela 1, observa-se que o critério custo total é o mais frequente nas modelagens pesquisadas, seguido pelos critérios preço da licença, custos de manutenção, consultoria, infraestrutura e manutenção. Observa-se também que, na dimensão financeira, tanto o número quanto a diversidade dos critérios utilizados nos modelos baseados em Fuzzy é inferior a encontrada nos modelos baseados no AHP - apenas dois artigos Fuzzy utilizaram mais do que um critério financeiro, ao passo que quatro artigos AHP utilizaram mais do que um critério financeiro.

A Tabela 2 apresenta os resultados referentes ao grupo de critérios denotado por: Negócio. Ao se analisar os dados reportados nesta tabela, observa-se que o critério geral Estratégia é o mais frequentes nas modelagens pesquisadas, seguido pelos critérios Risco e Benefício do investimento, o que mostra o interesse na relação Risco $\times$ Benefício como um elemento estratégico nos artigos analisados.

No critério Negócios observou-se uma semelhança quanto ao quantitativo de diferentes critérios utilizados nos modelos baseados em Fuzzy e o quantitativo utilizado nos modelos AHP.

A Tabela 3 apresenta os resultados referentes ao grupo de critérios denotado por: Software. Observa-se que os critérios mais presentes nas modelagens são "Tempo de Implementação"; "Funcionalidade"; "Integração entre módulos/modularidade"; e, "Confiabilidade". Observa-se também que nesta dimensão há maior variedade de critérios nos modelos baseados no AHP do que nos modelos baseados em Fuzzy. Outro registro a ser feito é que esta dimensão foi a que apresentou a maior variedade de critérios.

A Tabela 4 refere-se ao grupo de critérios Tecnológicos. Observa-se que, nesta dimensão, os subcritérios mais presentes nas modelagens são "Independência de Plataforma", "Sistemas de

Tabela 1. Consolidação de critérios FINANCEIROS para seleção de sistemas ERP.

\begin{tabular}{|c|c|c|c|c|c|c|c|c|c|c|c|c|c|c|c|c|}
\hline Subcritérios & A1 & A2 & A3 & A4 & A5 & A6 & A7 & A8 & F1 & F2 & F3 & F4 & F5 & F6 & F7 & F8 \\
\hline Custo total & & & $\mathrm{X}$ & $\mathrm{X}$ & $\mathrm{X}$ & $\mathrm{X}$ & & & & $\mathrm{X}$ & & $\mathrm{X}$ & & $\mathrm{X}$ & & \\
\hline Preço / Licença & & & & $\mathrm{X}$ & & $\mathrm{X}$ & & & & & & & $\mathrm{X}$ & & & \\
\hline Custo de Manutenção & & & & $\mathrm{X}$ & & $\mathrm{X}$ & & & & & & & $\mathrm{X}$ & & & \\
\hline Custo de Consultoria & & & & $\mathrm{X}$ & & $\mathrm{X}$ & & & & & & & $\mathrm{X}$ & & & \\
\hline Custo de Infraestrutura & & & & $\mathrm{X}$ & & $\mathrm{X}$ & & & & & & & & & & \\
\hline Custo de implementação & & & & & $\mathrm{X}$ & & & & & & & & & & & \\
\hline Custo de upgrade & & & & & $\mathrm{X}$ & & & & & & & & & & & \\
\hline Custo de desenvolvimento & & & & & & & $\mathrm{X}$ & & & & & & & & & \\
\hline Custo direto & & & & & & & & & & & $\mathrm{X}$ & & & & & \\
\hline Custo indireto & & & & & & & & & & & $\mathrm{X}$ & & & & & \\
\hline Custo do Software & & & & & & & & & & & & & $\mathrm{X}$ & & & \\
\hline Dívida e ativos & & & & & & & & $\mathrm{X}$ & & & & & & & & \\
\hline Fatura e recibo & & & & & & & & $\mathrm{X}$ & & & & & & & & \\
\hline Análise de custo & & & & & & & & $\mathrm{X}$ & & & & & & & & \\
\hline Processo do cliente & & & & & & & & $\mathrm{X}$ & & & & & & & & \\
\hline Impostos & & & & & & & & $\mathrm{X}$ & & & & & & & & \\
\hline Capacidade de investimento & & & & & & & & $\mathrm{X}$ & & & & & & & & \\
\hline Aquisição de matéria-prima & & & & & & & & $\mathrm{X}$ & & & & & & & & \\
\hline $\begin{array}{l}\text { Planejamento de recurso de } \\
\text { material }\end{array}$ & & & & & & & & $\mathrm{X}$ & & & & & & & & \\
\hline $\begin{array}{l}\text { Compras e informações } \\
\text { sobre planejamento }\end{array}$ & & & & & & & & $\mathrm{X}$ & & & & & & & & \\
\hline
\end{tabular}


Tabela 2. Consolidação de critérios do NEGÓCIO para seleção de sistemas ERP.

\begin{tabular}{|c|c|c|c|c|c|c|c|c|c|c|c|c|c|c|c|c|}
\hline Subcritérios & A1 & $\mathbf{A 2}$ & $\mathbf{A 3}$ & A4 & A5 & A6 & A7 & A8 & F1 & F2 & F3 & F4 & F5 & F6 & F7 & F8 \\
\hline Estratégia & & & $\mathrm{X}$ & & & & $\mathrm{X}$ & & & $\mathrm{X}$ & & $\mathrm{X}$ & & $\mathrm{X}$ & & \\
\hline $\begin{array}{l}\text { Alinhado com a estratégia } \\
\text { de negócio }\end{array}$ & & & & & & & $\mathrm{X}$ & & & & & & & & & \\
\hline $\begin{array}{l}\text { Alinhado com a estratégia } \\
\text { de tecnologia }\end{array}$ & & & & & & & $\mathrm{X}$ & & & & & & & & & \\
\hline Urgência de aquisição & & & & & & & $\mathrm{X}$ & & & & & & & & & \\
\hline $\begin{array}{l}\text { Importância para uma } \\
\text { empresa }\end{array}$ & & & & & & & $X$ & & & & & & & & & \\
\hline Risco & & & $\mathrm{X}$ & & & & & & & $\mathrm{X}$ & & & & $\mathrm{X}$ & & \\
\hline Benefício de investimento & & & $\mathrm{X}$ & & $\mathrm{X}$ & & & & & $\mathrm{X}$ & & & & $\mathrm{X}$ & & \\
\hline $\begin{array}{l}\text { Gerenciamento de } \\
\text { mudanças }\end{array}$ & & & $\mathrm{X}$ & & & & & & & & & & & & & \\
\hline Incerteza comercial & & & & & & & $\mathrm{X}$ & & & & & & & & & \\
\hline Tamanho do mercado & & & & & & & $\mathrm{X}$ & & & & & & & & & \\
\hline Intensidade competitiva & & & & & & & $\mathrm{X}$ & & & & & & & & & \\
\hline Política de produção & & & & & & & & $\mathrm{X}$ & & & & & & & & \\
\hline Estrutura de produção & & & & & & & & $\mathrm{X}$ & & & & & & & & \\
\hline Informação do cliente & & & & & & & & $\mathrm{X}$ & & & & & & & & \\
\hline Planejamento do projeto & & & & & & & & & & & & & $X$ & & & \\
\hline $\begin{array}{l}\text { Possibilidade de definir } \\
\text { objetivamente os conceitos }\end{array}$ & & & & & & & & & & & & & $\mathrm{X}$ & & & \\
\hline Políticas organizacionais & & & & & & & & & & & & & $\mathrm{X}$ & & & \\
\hline $\begin{array}{l}\text { Aumento da flexibilidade } \\
\text { da organização }\end{array}$ & & & & & & & & & $\mathrm{X}$ & & & & & & & \\
\hline $\begin{array}{l}\text { Melhoria da estrutura } \\
\text { organizacional }\end{array}$ & & & & & & & & & $\mathrm{X}$ & & & & & & & \\
\hline $\begin{array}{l}\text { Mais bem alinhado com a } \\
\text { estrutura organizacional }\end{array}$ & & & & & & & & & & & & $\mathrm{X}$ & & & & \\
\hline $\begin{array}{l}\text { Outras considerações } \\
\text { estratégicas }\end{array}$ & & & & & & & & & $\mathrm{X}$ & & & & & & & \\
\hline
\end{tabular}

gerenciamento de banco de dados / metadados" e "Transparência e melhor fluxo de informação". Este fato indica uma preocupação com a flexibilidade e a manutenibilidade.

A Tabela 5 apresenta os resultados referentes ao grupo de critérios denotado por: Fornecedor. Observa-se que os critérios mais presentes nas modelagens são "Reputação" e "Serviços/Suporte". Isto indica que há uma preocupação com o pós-venda do Fornecedor. Outro fato observado na Tabela 5, é que há maior frequência de artigos que se baseiam no AHP, do que na lógica Fuzzy.

\section{Proposta de conjunto de critérios para seleção de sistemas ERP}

Com base na síntese da revisão bibliográfica, elaborou-se uma proposta de um conjunto de critérios e subcritérios para a seleção de sistemas ERP. Os subcritérios foram agrupados em conjuntos afins, retirando-se: as redundâncias ou superposição de critérios; e os critérios não aderentes ao problema em questão. Além disso, alterou-se a estrutura de critérios de modo a serem compreendidos e utilizados tanto pelos decisores quanto pelos avaliadores. Observa-se também que alguns subcritérios dos critérios funcionalidade, confiabilidade, usabilidade, eficiência, manutenibilidade e portabilidade foram incorporados à proposta, devido à importância destacada na norma ABNT NBR ISO/IEC 9126-1 (ASSOCIAÇÃO..., 2003).

\section{1 Árvore de critérios proposta para seleção de sistemas ERP}

A Figura 1 apresenta uma árvore composta por cinco grupos de critérios (Financeiro, Negócio, Software, Tecnológico e Fornecedor) e seus respectivos subcritérios. As informações mais detalhadas sobre esses critérios e subcritérios, assim como o terceiro nível desta árvore, com um total de 45 subcritérios, encontram-se descritos na próxima seção. Nesta 
Tabela 3. Consolidação de critérios do SOFTWARE para seleção de sistemas ERP.

\begin{tabular}{|c|c|c|c|c|c|c|c|c|c|c|c|c|c|c|c|c|}
\hline Subcritérios & A1 & A2 & $\mathbf{A 3}$ & A4 & A5 & A6 & A7 & A8 & F1 & F2 & F3 & F4 & F5 & F6 & F7 & F8 \\
\hline Tempo de Implementação & & & & $\mathrm{X}$ & $\mathrm{X}$ & & & & $X$ & $\mathrm{X}$ & & $\mathrm{X}$ & $\mathrm{X}$ & $X$ & & \\
\hline Funcionalidade & & & $\mathrm{X}$ & $\mathrm{X}$ & & $\mathrm{X}$ & & & $\mathrm{X}$ & $\mathrm{X}$ & $\mathrm{X}$ & $\mathrm{X}$ & & $\mathrm{X}$ & $\mathrm{X}$ & $\mathrm{X}$ \\
\hline $\begin{array}{l}\text { Integração entre módulos/ } \\
\text { modularidade }\end{array}$ & & & & $\mathrm{X}$ & $\mathrm{X}$ & $\mathrm{X}$ & & & $\mathrm{X}$ & & $\mathrm{X}$ & $\mathrm{X}$ & $\mathrm{X}$ & & $\mathrm{X}$ & $\mathrm{X}$ \\
\hline Função fitness & & & & $\mathrm{X}$ & & $X$ & & & & & & & & & & \\
\hline Segurança-dados/processo & & $\mathrm{X}$ & & $\mathrm{X}$ & $\mathrm{X}$ & $\mathrm{X}$ & & $\mathrm{X}$ & & & & & & & & \\
\hline Documentação (Data) & & $\mathrm{X}$ & & & $X$ & & & & & & & & & & & \\
\hline $\begin{array}{l}\text { Consistência com os objetivos } \\
\text { da empresa }\end{array}$ & & & & & $\mathrm{X}$ & & & & & & & & & & & \\
\hline Solução vertical & & & & & $\mathrm{X}$ & & & & & & & & & & & \\
\hline $\begin{array}{l}\text { User friendliness (Fácil de } \\
\text { operar) }\end{array}$ & & & & $\mathrm{X}$ & $\mathrm{X}$ & $\mathrm{X}$ & & & & $\mathrm{X}$ & & & & $\mathrm{X}$ & & \\
\hline Fácil de aprender & & $X$ & & $X$ & $X$ & $X$ & & & & & & & & & & \\
\hline Fácil de customização & & $\mathrm{X}$ & & & $\mathrm{X}$ & & & & & & & $\mathrm{X}$ & & & & \\
\hline Padronização & & & & & & $X$ & & & & & & & & & & \\
\hline Fácil de manter & & & & & & $\mathrm{X}$ & & & & & & & & & & \\
\hline Integração com sistemas legados & & & & & & $\mathrm{X}$ & & & & & & $\mathrm{X}$ & & & & \\
\hline Maior transparência & & & & & $\mathrm{X}$ & & & & & & & & & & & \\
\hline$S w$ com sucesso comprovado & & & & & $\mathrm{X}$ & & & & & & & & & & & \\
\hline Internacionalidade do $S w$ & & & & & $\mathrm{X}$ & & & & $\mathrm{X}$ & & & & & & & \\
\hline Escalabilidade & & & & & $\mathrm{X}$ & & & & & & & & & & & \\
\hline $\begin{array}{l}\text { Capacidade de gerar relatórios } \\
\text { de modo rápido e eficaz }\end{array}$ & & & & & & & & $\mathrm{X}$ & & & & & & & & \\
\hline Implementabilidade & & & $\mathrm{X}$ & & & & & & & & & & & & & \\
\hline Flexibilidade & & & $\mathrm{X}$ & $\mathrm{X}$ & $\mathrm{X}$ & $\mathrm{X}$ & & & $\mathrm{X}$ & & & & & & & \\
\hline Habilidade de upgrade & & & & $\mathrm{X}$ & & $\mathrm{X}$ & & & & $\mathrm{X}$ & & & & $X$ & & \\
\hline Fácil de integração & & & & $\mathrm{X}$ & & $\mathrm{X}$ & & & & & & & & & & \\
\hline Fácil desenvolvimento in-house & & & & $\mathrm{X}$ & $\mathrm{X}$ & $\mathrm{X}$ & & & $\mathrm{X}$ & & & & & & & \\
\hline Adaptabilidade & & & & & $\mathrm{X}$ & & & & & & & & & & & \\
\hline Confiabilidade & & & & $\mathrm{X}$ & $\mathrm{X}$ & $\mathrm{X}$ & & & $\mathrm{X}$ & $\mathrm{X}$ & & $\mathrm{X}$ & $\mathrm{X}$ & $\mathrm{X}$ & $\mathrm{X}$ & $\mathrm{X}$ \\
\hline Estabilidade & & & & $\mathrm{X}$ & $\mathrm{X}$ & $\mathrm{X}$ & & & & & & & & & & \\
\hline Habilidade de recuperação & & & & $\mathrm{X}$ & & $\mathrm{X}$ & & & & & & & & & & \\
\hline $\begin{array}{l}\text { Funcionalidade ETL (extração, } \\
\text { transformação e carga) }\end{array}$ & & & & & & & & & & & $\mathrm{X}$ & & & & & \\
\hline $\begin{array}{l}\text { Visibilidade das transações } \\
\text { detalhadas }\end{array}$ & & & & & & & & & $\mathrm{X}$ & & & & & & & \\
\hline Capacidade & & & & & & & & & $\mathrm{X}$ & & & & & & & \\
\hline Credibilidade & & & & & & & & & $\mathrm{X}$ & & & & $\mathrm{X}$ & & & \\
\hline $\begin{array}{l}\text { Compatibilidade com outros } \\
\text { sistemas }\end{array}$ & & & & & & & & & & & $\mathrm{X}$ & $\mathrm{X}$ & & & & \\
\hline Conversão da moeda & & & & & & & & & $\mathrm{X}$ & & & & & & & \\
\hline Metodologia do $S W$ & & & & & & & & & & & & $\mathrm{X}$ & & & & \\
\hline $\begin{array}{l}\text { Alinhados com os sistemas da } \\
\text { organização }\end{array}$ & & & & & & & & & & & & $\mathrm{X}$ & & & & \\
\hline $\begin{array}{l}\text { Possibilidade de aplicar soluções } \\
\text { da indústria }\end{array}$ & & & & & & & & & & & & $\mathrm{X}$ & & & & \\
\hline $\begin{array}{l}\text { Adaptação do sistema ERP } \\
\text { com as necessidades atuais da } \\
\text { empresa }\end{array}$ & & & & & & & & & & & & & $\mathrm{X}$ & & & \\
\hline $\begin{array}{l}\text { Capacidade do sistema ERP } \\
\text { oferecer informações "On-time" }\end{array}$ & & & & & & & & & & & & & $\mathrm{X}$ & & & \\
\hline Intuitividade do sistema ERP & & & & & & & & & & & & & $\mathrm{X}$ & & & \\
\hline
\end{tabular}


Tabela 3. Continuação...

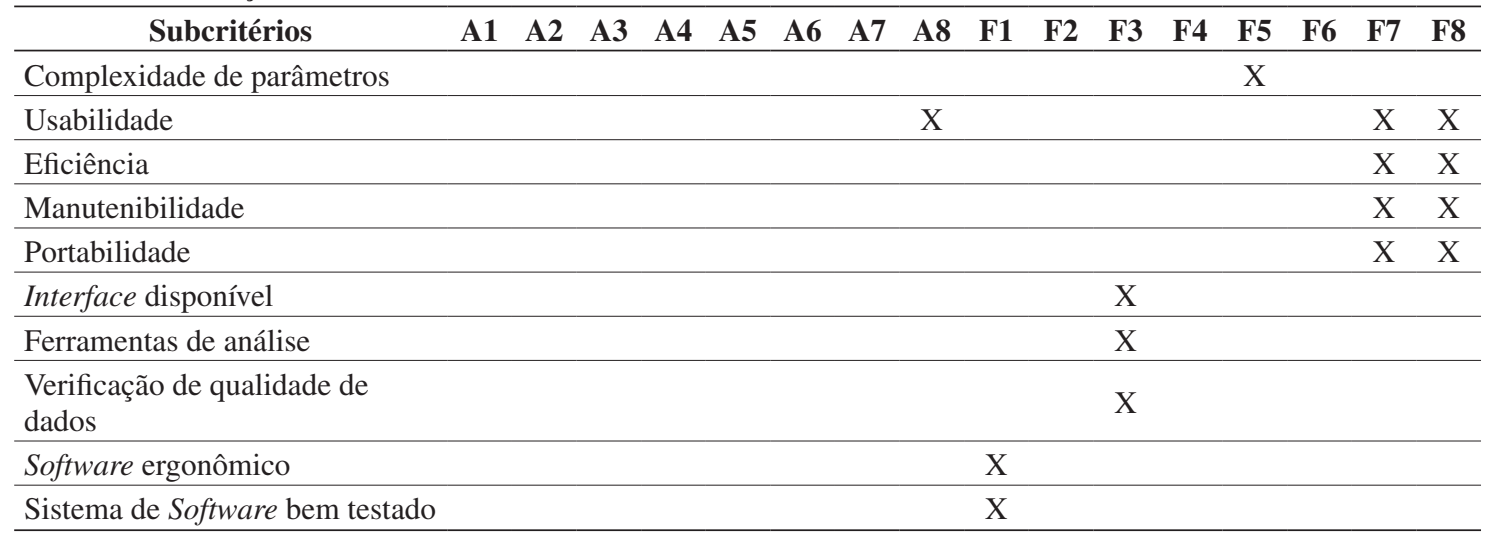

Tabela 4. Consolidação de critérios TECNOLÓGICOS para seleção de sistemas ERP.

\begin{tabular}{|c|c|c|c|c|c|c|c|c|c|c|c|c|c|c|c|c|}
\hline Subcritérios & A1 & A2 & A3 & A4 & A5 & A6 & A7 & A8 & F1 & F2 & F3 & F4 & F5 & F6 & F7 & F8 \\
\hline Tecnologia & & & $\mathrm{X}$ & & & & $\mathrm{X}$ & & & & & $\mathrm{X}$ & & & & \\
\hline Independência de Plataforma & & $\mathrm{X}$ & & & $\mathrm{X}$ & & & & & & & & & & $\mathrm{X}$ & $\mathrm{X}$ \\
\hline Requerimentos do Hardware & & $\mathrm{X}$ & & & $\mathrm{X}$ & & & & & & & & $\mathrm{X}$ & & & \\
\hline Ciclo de vida tecnológico & & & & & & & $\mathrm{X}$ & & & & & & & & & \\
\hline Afinidade tecnológica & & & & & & & $\mathrm{X}$ & & & & & & & & & \\
\hline Facilidade de imitar & & & & & & & $\mathrm{X}$ & & & & & & & & & \\
\hline Ambiente com regime apropriado & & & & & & & $\mathrm{X}$ & & & & & & & & & \\
\hline Disponibilidade de fonte externa & & & & & & & $\mathrm{X}$ & & & & & & & & & \\
\hline Qualidade de tecnologia externa & & & & & & & $\mathrm{X}$ & & & & & & & & & \\
\hline Dinamismo & & & & & & & $\mathrm{X}$ & & & & & & & & & \\
\hline $\begin{array}{l}\text { Melhorias serviço Internet } \mathrm{e} \\
\text { e-commerce }\end{array}$ & & & & & $\mathrm{X}$ & & & & & & & & & & & \\
\hline $\begin{array}{l}\text { Dados de máquina e } \\
\text { equipamento }\end{array}$ & & & & & & & & $\mathrm{X}$ & & & & & & & & \\
\hline $\begin{array}{l}\text { Sistemas de gerenciamento de } \\
\text { banco de dados / metadados }\end{array}$ & & & & & & & & & $\mathrm{X}$ & & $\mathrm{X}$ & & & & $X$ & $\mathrm{X}$ \\
\hline $\begin{array}{l}\text { Administração de data } \\
\text { warehouse }\end{array}$ & & & & & & & & & & & $X$ & & & & & \\
\hline $\begin{array}{l}\text { Linguagens e ferramentas de } \\
\text { desenvolvimento/Adoção de } S w\end{array}$ & & & & & & & & & $\mathrm{X}$ & & & & & & $X$ & $\mathrm{X}$ \\
\hline $\begin{array}{l}\text { Ferramentas de gerenciamento } \\
\text { do usuário }\end{array}$ & & & & & & & & & & & & & & & $\mathrm{X}$ & $\mathrm{X}$ \\
\hline Conectividade externa & & & & & & & & & & & & & & & $\mathrm{X}$ & $\mathrm{X}$ \\
\hline Documentação do usuário & & & & & & & & & & & & & & & $\mathrm{X}$ & $\mathrm{X}$ \\
\hline Documentação técnica & & & & & & & & & & & & & & & $\mathrm{X}$ & $\mathrm{X}$ \\
\hline $\begin{array}{l}\text { Conceitos de avaliação e controle } \\
\text { de versão }\end{array}$ & & & & & & & & & & & & & & & $\mathrm{X}$ & $\mathrm{X}$ \\
\hline Padrão de interface & & & & & & & & & & & & & & & $\mathrm{X}$ & $\mathrm{X}$ \\
\hline Estrutura e estilo de arquitetura & & & & & & & & & & & & & & & $\mathrm{X}$ & $\mathrm{X}$ \\
\hline $\begin{array}{l}\text { Transparência e melhor fluxo de } \\
\text { informação }\end{array}$ & $X$ & & & & & & & & $\mathrm{X}$ & & & & & & $\mathrm{X}$ & $\mathrm{X}$ \\
\hline $\begin{array}{l}\text { Independência operacional do } \\
\text { sistema }\end{array}$ & $\mathrm{X}$ & & & & & & & & $\mathrm{X}$ & & & & & & & \\
\hline
\end{tabular}


Tabela 5. Consolidação de critérios do FORNECEDOR para seleção de sistemas ERP.

\begin{tabular}{|c|c|c|c|c|c|c|c|c|c|c|c|c|c|c|c|c|}
\hline Subcritérios & A1 & A2 & A3 & A4 & A5 & A6 & A7 & A8 1 & F1 & F2 & F3 & F4 & F5 & F6 & F7 & F8 \\
\hline Reputação & $\mathrm{X}$ & & $\mathrm{X}$ & $\mathrm{X}$ & $\mathrm{X}$ & $\mathrm{X}$ & & & & $\mathrm{X}$ & $\mathrm{X}$ & & & $\mathrm{X}$ & $\mathrm{X}$ & $X$ \\
\hline Capacidade técnica & & & $\mathrm{X}$ & $\mathrm{X}$ & $\mathrm{X}$ & $X$ & & & & & & & & & & \\
\hline Treinamento & $X$ & & & $\mathrm{X}$ & $\mathrm{X}$ & $X$ & & & & & & & & & & \\
\hline Suporte Implantação & $\mathrm{X}$ & & & $\mathrm{X}$ & & $\mathrm{X}$ & & & & & & & & & & \\
\hline Serviço / Suporte & & & $\mathrm{X}$ & $\mathrm{X}$ & $\mathrm{X}$ & $\mathrm{X}$ & & & $\mathrm{X}$ & & $\mathrm{X}$ & $\mathrm{X}$ & & & $\mathrm{X}$ & $\mathrm{X}$ \\
\hline Suporte infraestrutura & & & $\mathrm{X}$ & & & & & & & & & & & & & \\
\hline Resposta a problemas & & & & $\mathrm{X}$ & $X$ & $X$ & & & & & & & & & & \\
\hline Tamanho do fornecedor & & & & & $\mathrm{X}$ & & $\mathrm{X}$ & & & & & & & & & \\
\hline Solidez financeira & & & & $\mathrm{X}$ & $\mathrm{X}$ & & & & & $X$ & & & & $X$ & & \\
\hline $\begin{array}{l}\text { Disponibilidade de recurso para } \\
\text { modificação }\end{array}$ & & & & $\mathrm{X}$ & $\mathrm{X}$ & & & & & & & & & & & \\
\hline Número de clientes & & & & & $\mathrm{X}$ & & & & & & & & & & & \\
\hline Habilidade/Experiência de P\&D & & & $\mathrm{X}$ & $\mathrm{X}$ & & $\mathrm{X}$ & $\mathrm{X}$ & & & & & & & & & \\
\hline Tecnologia de P\&D & & & & & & & $\mathrm{X}$ & & & $X$ & & & & $\mathrm{X}$ & $X$ & $\mathrm{X}$ \\
\hline Mão de obra de P\&D & & & & & & & $\mathrm{X}$ & & & & & & & & & \\
\hline Velocidade do Serviço & & & & $\mathrm{X}$ & $\mathrm{X}$ & $\mathrm{X}$ & & & & & & & & & & \\
\hline Garantias & & & & $\mathrm{X}$ & & & & & & & & & & & & \\
\hline $\begin{array}{l}\text { Comunicação entre clientes e } \\
\text { fornecedores }\end{array}$ & & & & & $\mathrm{X}$ & & & & & & & & & & & \\
\hline Serviço de consultoria & & & & $\mathrm{X}$ & & $\mathrm{X}$ & & & & $\mathrm{X}$ & & & & $\mathrm{X}$ & $\mathrm{X}$ & $\mathrm{X}$ \\
\hline $\begin{array}{l}\text { Posição tecnológica do } \\
\text { fornecedor }\end{array}$ & & & & & $\mathrm{X}$ & & $\mathrm{X}$ & & & & & & & & & \\
\hline Ativos complementares & & & & & & & $\mathrm{X}$ & & & & & & & & & \\
\hline $\begin{array}{l}\text { Referências e credenciais do } \\
\text { fornecedor }\end{array}$ & & & & & & & & & & $\mathrm{X}$ & & $\mathrm{X}$ & & $\mathrm{X}$ & & \\
\hline $\begin{array}{l}\text { Implementação e habilidade } \\
\text { para o serviço }\end{array}$ & & & & & & & & & & $\mathrm{X}$ & & & & $\mathrm{X}$ & $\mathrm{X}$ & $\mathrm{X}$ \\
\hline Suporte a treinamento & & & & & & & & & & $\mathrm{X}$ & & & & $\mathrm{X}$ & $\mathrm{X}$ & $\mathrm{X}$ \\
\hline Suporte a banco de dados & & & & & & & & & & & $X$ & & & & & \\
\hline Experiência do fornecedor & & & & & & & & & & & $\mathrm{X}$ & & & & & \\
\hline Estabilidade do fornecedor & & & & & & & & & & & $\mathrm{X}$ & & & & & \\
\hline $\begin{array}{l}\text { Requerimentos da equipe } \\
\text { especialista }\end{array}$ & & & & & & & & & & & & & $\mathrm{X}$ & & & \\
\hline $\begin{array}{l}\text { Maior transparência e melhor } \\
\text { fluxo de informação }\end{array}$ & & & & & & & & & $\mathrm{X}$ & & & & & & & \\
\hline Suporte a várias linguagens & & & & & & & & & $\mathrm{X}$ & & & & & & & \\
\hline Posição de mercado do fornecedor & & & & & & & & & $\mathrm{X}$ & & & $\mathrm{X}$ & & & & \\
\hline Serviço de suporte a vários países & & & & & & & & & $\mathrm{X}$ & & & & & & & \\
\hline $\begin{array}{l}\text { Domínio de conhecimento do } \\
\text { fornecedor }\end{array}$ & & & & & & & & & & & & $\mathrm{X}$ & & & & \\
\hline
\end{tabular}

hierarquia, o critério Negócio refere-se ao alinhamento com o Negócio da organização.

A árvore de critérios ilustrada na Figura 1 apresenta a estrutura de critérios e subcritérios obtida após este processo de construção e validação apresentado a seguir:

- Elaboração de revisão bibliográfica sistematizada em artigos disponibilizados em periódicos científicos indexados nas bases SCOPUS, ISI
(Web of Knowledge) e Engineering Village buscando identificar artigos que aplicassem alguma abordagem multicritério na seleção de sistemas ERP;

- Com base no conhecimento obtido na revisão bibliográfica foi elaborada uma compilação de critérios e subcritérios, a qual foi submetida à validação junto a um grupo de Especialistas de TI - Tecnologia da Informação (“grupo focal”), 
selecionados por sua grande experiência em seleção de sistemas de informação gerenciais. Neste processo, foram realizadas entrevistas individuais com os especialistas, aos quais era apresentada a estrutura de critérios e subcritérios elaborada com base na revisão da literatura; e

- Os resultados das entrevistas foram compilados e retornados por e-mail aos especialistas entrevistados, obtendo-se o consenso entre os especialistas quanto à estrutura de critérios e subcritérios.

A Tabela 6 apresenta a descrição dos 45 subcritérios do nível mais baixo da hierarquia da árvore apresentada na Figura 1, indicando a qual subcritério estão subordinados. Por exemplo: o subcritério de nível mais baixo "custo inicial" está subordinado ao subcritério "custo financeiro" o qual está subordinado ao critério "financeiro"; ao passo que o subcritério de nível mais baixo "interoperabilidade" está subordinado ao subcritério "funcionalidade" no critério "Software".

\section{Mapeamento da percepção de importância dos critérios: pesquisa de campo}

Foi aplicado um questionário on-line para mapear a importância de critérios e subcritérios usados na seleção de sistemas integrados de gestão (ERP) para a Indústria da Construção Civil. Antes de ser enviado, o questionário foi testado e validado por especialistas experientes em seleção de sistemas ERP. Algumas revisões foram realizadas de modo a garantir que o questionário fosse mais compreensível e abrangente. A pesquisa foi realizada no período de fevereiro/2011 a abril/2011, e a análise dos resultados foi realizada de março/2011 a junho/2011.

A pesquisa foi composta por 23 perguntas: as cinco primeiras introdutórias, sobre o perfil profissional do entrevistado e, as demais 18 perguntas, se referem à atribuição de pesos aos critérios e subcritérios propostos. Para essas 18 perguntas, foi informado que a soma dos pesos atribuídos aos critérios, em cada pergunta, tinha que ser sempre igual a 100 .

Tabela 6. Subcritérios do nível mais baixo da hierarquia.

\begin{tabular}{|c|c|c|c|}
\hline Critérios & Subcritérios & $\begin{array}{l}\text { Subcritérios de nível mais } \\
\text { baixo }\end{array}$ & Descrição \\
\hline \multirow{8}{*}{ Financeira } & \multirow{4}{*}{ Custo total } & Custo inicial & $\begin{array}{l}\text { Custo de aquisição, licença, clients instalados, rede, } \\
\text { comunicação e instalação de todo o software e } \\
\text { hardware necessários à implantação do sistema. }\end{array}$ \\
\hline & & Custo de Implementação & $\begin{array}{l}\text { Custo de mudanças procedurais, consultoria, } \\
\text { customizações e adaptações do sistema. }\end{array}$ \\
\hline & & Custo de Treinamento & $\begin{array}{l}\text { Custo de treinamento dos usuários na utilização do } \\
\text { sistema. }\end{array}$ \\
\hline & & Custo de Manutenção & $\begin{array}{l}\text { Custo para manutenção do sistema, uma vez já } \\
\text { implementado e custo de upgrade (atualização) do } \\
\text { sistema quando uma nova versão for lançada. }\end{array}$ \\
\hline & \multirow{4}{*}{$\begin{array}{l}\text { Condições } \\
\text { contratuais }\end{array}$} & Condições comerciais & $\begin{array}{l}\text { Condições do pagamento do produto ou serviço, com } \\
\text { relação à licença, leasing, implementação, treinamento } \\
\text { e direitos sobre o código fonte, sobre versões e } \\
\text { upgrades. }\end{array}$ \\
\hline & & Fornecimento de serviço & $\begin{array}{l}\text { Fornecimento dos tipos de serviços: SaaS } \\
\text { (Software como serviço), IaaS(Infraestrutura), } \\
\text { CaaS(Comunicação), DaaS (Desenvolvimento), PaaS } \\
\text { (Plataforma). }\end{array}$ \\
\hline & & Garantia & $\begin{array}{l}\text { Termos de garantia de prestação de serviços e de } \\
\text { qualidade do sistema. }\end{array}$ \\
\hline & & $\begin{array}{l}\text { SLA (Acordo de nível de } \\
\text { serviço) }\end{array}$ & $\begin{array}{l}\text { O nível da prestação de serviço é definido } \\
\text { formalmente e existem mecanismos de } \\
\text { monitoramento dos indicadores. }\end{array}$ \\
\hline \multirow{4}{*}{ Negócio } & \multirow{4}{*}{ Estratégia } & $\begin{array}{l}\text { Alinhamento com a estratégia } \\
\text { de negócio }\end{array}$ & $\begin{array}{l}\text { O sistema está alinhado à estratégia de negócio da } \\
\text { empresa adotante. }\end{array}$ \\
\hline & & $\begin{array}{l}\text { Alinhamento com a estratégia } \\
\text { de tecnologia }\end{array}$ & $\begin{array}{l}\text { O sistema está alinhado à estratégia de tecnologia da } \\
\text { empresa adotante. }\end{array}$ \\
\hline & & Gerenciamento de mudanças & $\begin{array}{l}\text { Existem procedimentos de gerenciamento de } \\
\text { mudanças do sistema. }\end{array}$ \\
\hline & & Política de produção & $\begin{array}{l}\text { Existe política de produção (procedimentos de } \\
\text { backup, recuperação, limpezas etc.) do sistema. }\end{array}$ \\
\hline
\end{tabular}


Tabela 6. Continuação...

\begin{tabular}{|c|c|c|c|}
\hline Critérios & Subcritérios & $\begin{array}{l}\text { Subcritérios de nível mais } \\
\text { baixo }\end{array}$ & Descrição \\
\hline \multirow{18}{*}{ Software } & \multirow{3}{*}{ Tempo } & Tempo de implementação & $\begin{array}{l}\text { Tempo gasto com mudanças procedurais, consultoria, } \\
\text { customizações e adaptações do sistema. }\end{array}$ \\
\hline & & Tempo de treinamento & $\begin{array}{l}\text { Tempo requerido para treinar todos os usuários a } \\
\text { aprender a utilizar o sistema na operação do dia a dia. }\end{array}$ \\
\hline & & Tempo de produção & $\begin{array}{l}\text { Tempo gasto na operação do sistema (procedimentos } \\
\text { de backup, recuperação, limpeza etc.). }\end{array}$ \\
\hline & \multirow{5}{*}{ Funcionalidade } & Adequação (Função fitness) & $\begin{array}{l}\text { Mede o quanto o conjunto de funcionalidades é } \\
\text { adequado às necessidades do usuário. É desejável } \\
\text { que o sistema tenha solução vertical para atender ao } \\
\text { setor da construção civil. }\end{array}$ \\
\hline & & Interoperabilidade & $\begin{array}{l}\text { O sistema pode ser facilmente integrado com outros } \\
\text { sistemas. }\end{array}$ \\
\hline & & Conformidade & $\begin{array}{l}\text { Faz com que o sistema esteja de acordo com as normas, } \\
\text { convenções ou regulamentações previstas em leis e } \\
\text { descrições similares, relacionadas à aplicação. }\end{array}$ \\
\hline & & Manutenibilidade & $\begin{array}{l}\text { A capacidade do sistema ser modificado, incluindo } \\
\text { tanto as melhorias ou extensões de funcionalidade } \\
\text { quanto as correções de defeitos, assim como upgrades. }\end{array}$ \\
\hline & & Customização & Facilidade de fazer customizações no sistema. \\
\hline & \multirow{3}{*}{ Usabilidade } & Facilidade de uso & Facilidade de uso do sistema por parte do usuário \\
\hline & & $\begin{array}{c}\text { Criação de aplicações pelo } \\
\text { usuário }\end{array}$ & $\begin{array}{l}\text { Facilidade do usuário de criar novas aplicações pela } \\
\text { exploração e consolidação dos dados e da geração de } \\
\text { telas e relatórios, para atender as suas necessidades } \\
\text { específicas. }\end{array}$ \\
\hline & & Eficiência & $\begin{array}{l}\text { Nível de desempenho do sistema de acordo com a } \\
\text { quantidade de recursos usados. }\end{array}$ \\
\hline & \multirow{3}{*}{ Flexibilidade } & $\begin{array}{l}\text { Facilidade desenvolvimento } \\
\text { in-house }\end{array}$ & $\begin{array}{l}\text { Facilidade de realizar desenvolvimento interno } \\
\text { (in-house) no sistema. }\end{array}$ \\
\hline & & Escalabilidade & $\begin{array}{l}\text { Capacidade do sistema em suportar um aumento de } \\
\text { carga quando os recursos são requeridos. }\end{array}$ \\
\hline & & Portabilidade & $\begin{array}{l}\text { Capacidade do sistema ser transferido de um } \\
\text { ambiente para o outro. }\end{array}$ \\
\hline & \multirow{4}{*}{ Confiabilidade } & Maturidade & $\begin{array}{l}\text { Representa a capacidade do sistema em evitar falhas } \\
\text { decorrentes de defeitos no sistema, mantendo um } \\
\text { nível estável de qualidade. }\end{array}$ \\
\hline & & Tolerância a falhas & $\begin{array}{l}\text { Evidencia a capacidade em manter um nível de } \\
\text { desempenho especificado nos casos de falhas no } \\
\text { sistema ou de violação nas interfaces especificadas. }\end{array}$ \\
\hline & & Recuperabilidade & $\begin{array}{l}\text { Representa a capacidade de restabelecer o nível de } \\
\text { desempenho e recuperar os dados diretamente afetados, } \\
\text { em caso de falha, e no tempo e esforço necessários para tal. }\end{array}$ \\
\hline & & Segurança & $\begin{array}{l}\text { Representa a capacidade de evitar o acesso não } \\
\text { autorizado, acidental ou deliberado, a programas e } \\
\text { dados do sistema. }\end{array}$ \\
\hline \multirow{6}{*}{ Tecnológico } & \multirow{3}{*}{$\begin{array}{l}\text { Plataforma } \\
\text { Tecnológica }\end{array}$} & Independência de Plataforma & $\begin{array}{l}\text { O sistema pode ser instalado em diferentes tipos de } \\
\text { plataforma. }\end{array}$ \\
\hline & & $\begin{array}{l}\text { Adequação da arquitetura } \\
\text { técnica }\end{array}$ & $\begin{array}{l}\text { A estrutura de arquitetura técnica do sistema está de } \\
\text { acordo com a plataforma da empresa adotante. }\end{array}$ \\
\hline & & $\begin{array}{l}\text { Linguagens e ferramentas de } \\
\text { desenvolvimento }\end{array}$ & $\begin{array}{l}\text { As linguagens e ferramentas de desenvolvimento } \\
\text { do sistema estão alinhadas com a política de TI da } \\
\text { empresa adotante. }\end{array}$ \\
\hline & \multirow{3}{*}{ Serviços } & Serviço Internet & O sistema se utiliza das facilidades de uso da internet. \\
\hline & & Documentação do usuário & $\begin{array}{l}\text { A documentação sobre o uso do sistema é de fácil } \\
\text { compreensão por parte do usuário da empresa adotante. }\end{array}$ \\
\hline & & Documentação técnica & $\begin{array}{l}\text { A documentação técnica a ser utilizada pelos analistas } \\
\text { de TI da empresa adotante é de fácil compreensão. }\end{array}$ \\
\hline
\end{tabular}


Tabela 6. Continuação...

\begin{tabular}{|c|c|c|c|}
\hline Critérios & Subcritérios & $\begin{array}{l}\text { Subcritérios de nível mais } \\
\text { baixo }\end{array}$ & Descrição \\
\hline \multirow{9}{*}{ Fornecedor } & \multirow{3}{*}{$\begin{array}{l}\text { Perfil do } \\
\text { Fornecedor }\end{array}$} & Solidez financeira & $\begin{array}{l}\text { Existe solidez financeira por parte do fornecedor } \\
\text { do sistema e estabilidade de modo a garantir a } \\
\text { continuidade do produto. }\end{array}$ \\
\hline & & Referências & $\begin{array}{l}\text { Avaliação dos clientes com relação aos serviços } \\
\text { prestados pelo fornecedor e existência de clientes } \\
\text { representativos. }\end{array}$ \\
\hline & & $\begin{array}{c}\text { Sustentabilidade e } \\
\text { Responsabilidade Social }\end{array}$ & $\begin{array}{l}\text { O fornecedor do sistema está comprometido com a } \\
\text { sustentabilidade e responsabilidade social em sua } \\
\text { empresa. }\end{array}$ \\
\hline & \multirow{3}{*}{$\begin{array}{l}\text { Capacidade } \\
\text { técnica }\end{array}$} & Disponibilidade de recursos & $\begin{array}{l}\text { O fornecedor tem disponibilidade de recursos } \\
\text { adequados e qualificados para realizar os serviços } \\
\text { contratados pelo cliente, assim como tem facilidade } \\
\text { em formar consultores. }\end{array}$ \\
\hline & & Tecnologia P\&D & $\begin{array}{l}\text { O fornecedor do sistema investe em treinamento, } \\
\text { pesquisa e desenvolvimento (P\&D), demonstrando } \\
\text { habilidade e experiência em P\&D. }\end{array}$ \\
\hline & & Experiência do fornecedor & $\begin{array}{l}\text { O fornecedor tem experiência em implementação de } \\
\text { sistema ERP em outras empresas do mesmo setor. }\end{array}$ \\
\hline & \multirow{3}{*}{ Suporte } & Serviço de suporte & $\begin{array}{l}\text { Fornece serviços adequados de help-desk, consultoria, } \\
\text { de manutençâo, de desenvolvimento, de infraestrutura, } \\
\text { assim como fornece suporte a vários países } \\
\text { (abrangência geográfica). }\end{array}$ \\
\hline & & $\begin{array}{l}\text { Relacionamento entre clientes } \\
\text { e fornecedores }\end{array}$ & $\begin{array}{l}\text { Existe uma boa relação e comunicação entre o } \\
\text { fornecedor do sistema e os usuários da empresa } \\
\text { adotante. }\end{array}$ \\
\hline & & Tempo de atendimento & $\begin{array}{l}\text { O fornecedor do sistema tem capacidade de responder } \\
\text { com rapidez às solicitações de serviços dos usuários. }\end{array}$ \\
\hline
\end{tabular}

\subsection{Amostra pesquisada}

O questionário foi aplicado a profissionais atuantes nas áreas de TI (Tecnologia da Informação), Construção Civil, assim como na área de Educação e Outros, justamente por ser um grupo composto por pessoas que puderam dar grandes contribuições para a seleção de sistemas ERP para empresas da Construção Civil. Geograficamente, as empresas e os especialistas entrevistados estavam situados nos estados do Rio de Janeiro, São Paulo e Minas Gerais. Observou-se, nas respostas da primeira parte do questionário, que havia um subgrupo com maior aderência TI. Este fato levou à organização da amostra pesquisada em dois subgrupos. O primeiro grupo, composto por todos os 79 respondentes pesquisados. O segundo, composto por 32 respondentes. Os respondentes integrantes da segunda amostra foram selecionados da primeira amostra por terem maior afinidade com o tema, ou seja: são integrantes das duas amostras. Esses 32 respondentes trabalharam ou estiveram envolvidos com a implementação de sistemas integrados de gestão (ERP).

A seguir, apresentam-se os resultados da pesquisa sobre o perfil do profissional entrevistado e sobre a atribuição de pesos aos critérios e subcritérios, sendo identificada a importância relativa dos pesos médios dos subcritérios por grupos de critérios, assim como faz-se uma análise comparativa dos resultados das duas amostras pesquisadas.

\subsection{Resultados sobre o perfil do profissional entrevistado}

Com relação ao perfil dos profissionais entrevistados, observa-se que a maioria dos 79 e 32 respondentes trabalha em organizações cuja área predominante é TI ou Construção Civil. A maioria dos respondentes atua predominantemente na área de TI, com mais de 10 anos de experiência nesta área. Além disso, observa-se que a maioria dos respondentes declarou utilizar P-ERP (ERP proprietário) em sua organização.

Com relação ao envolvimento dos 79 respondentes na implementação de sistemas ERP, a maioria (60\% ou 47 respondentes) não chegou a implementar. Os demais $40 \%$, que correspondem aos 32 respondentes que fazem parte da segunda amostra pesquisa, estão assim distribuídos: 25\% (20 respondentes) já implementaram P-ERP e 10\% (8 respondentes) implementaram interfaces entre o P-ERP e os sistemas legados; os restantes implementaram FOS-ERP (4\% ou 3 respondentes) assim como interfaces entre o FOS_ERP e os sistemas legados (1\% ou 1 respondente). 


\subsection{Resultados da análise comparativa dos critérios dos dois primeiros níveis da hierarquia}

Foram utilizados gráficos comparativos para descrever os resultados referentes às perguntas 6 , 7, 11, 17 e 20, que representam os dois primeiros níveis de critérios da estrutura proposta. Para as outras perguntas, que correspondem aos subcritérios do nível mais baixo da hierarquia, será apresentada uma análise comparativa na seção 6.4 , por meio da Tabela 7 e de gráficos comparativos. Os valores utilizados nos gráficos, a seguir, equivalem às médias aritméticas dos pesos atribuídos pelos respondentes a cada um dos critérios e subcritérios.

Observa-se, na Figura 2, que, para ambas as amostras pesquisadas, os critérios mais importantes são: Financeiro, Negócio e Software, seguidos pelos critérios Fornecedor e Tecnológico. Esta Figura 2 também indica que o grupo de 32 respondentes consideraram maior importância ao Fornecedor, quando comparada à importância atribuída a este critério pelo grupo de 79 respondentes. Este resultado se justifica pelo fato de o primeiro grupo estar mais focado na área de TI.

A Figura 3 corresponde à distribuição das respostas válidas da pergunta 7 , apresentando o resultado referente aos subcritérios do Critério Financeiro, indicando que o custo total tem maior importância do que as condições contratuais para ambas as amostras. No entanto, observa-se que a diferença entre os valores atribuídos às importâncias é maior para o grupo de 32 respondentes.

A Figura 4 apresenta o resultado referente à distribuição das respostas válidas da pergunta 11. Observa-se que as respostas do grupo de 79 respondentes indicou que a confiabilidade $(23 \%) \mathrm{e}$ funcionalidade (23\%) têm maior importância, seguida da usabilidade (20\%), flexibilidade (18\%) e tempo (16\%). Já as repostas do grupo de 32 respondentes consideraram que a confiabilidade (26\%) tem maior importância, seguida da funcionalidade (23\%), usabilidade (19\%), flexibilidade (17\%) e tempo (15\%).

A Figura 5 ilustra a distribuição das respostas válidas da pergunta 17 , referentes às importâncias relativas dos subcritérios que compõem o Critério Tecnológico. Estes resultados indicam que ambos os grupos consideram Serviços mais importante do que Plataforma.

A Figura 6 apresenta o resultado referente à distribuição das importâncias relativas, atribuídas pelo grupo de 79 respondentes, dos subcritérios, no contexto do Critério do Fornecedor, indicando que a capacidade técnica (36\%) tem maior importância, seguida do suporte $(35 \%)$ e perfil do fornecedor (29\%). Este gráfico também ilustra que, para o grupo de 32 respondentes, a capacidade técnica (36\%) e o suporte $(36 \%)$ têm maior importância que o perfil do fornecedor $(28 \%)$.

\subsection{Resultados da análise comparativa dos subcritérios do nível mais baixo da hierarquia}

Nesta seção, faz-se uma análise comparativa entre os resultados dos pesos médios atribuídos aos subcritérios do nível mais baixo da hierarquia da árvore, pelas duas amostras, ou seja, pelos grupos de 79 e 32 respondentes, que se encontram compilados na Tabela 7, ilustrados graficamente na Figura 7.

Para melhor visualização, foram realizados cinco gráficos agrupados pelos Critérios do mais alto nível da hierarquia: Financeiro, Negócio, Software, Tecnológico e Fornecedor.

A Figura 8 (Financeiro) que, com relação aos subcritérios de custo total, o custo de manutenção e o custo de implementação foram considerados os mais importantes pelas duas amostras, seguidos pelo custo inicial e de treinamento. Também, observa-se nos subcritérios de condições contratuais, que o SLA e garantia ficaram com maior peso médio em relação aos demais subcritérios, fornecimento de serviços e condições comerciais, cujos pesos estão similares.

A Figura 9 (Negócio) ilustra que o alinhamento com a estratégia de negócio foi o subcritério que mais se destacou, seguido do alinhamento com a estratégia de tecnologia, gerenciamento de mudanças e política de produção, que ficou com o menor peso médio, segundo a opinião dos dois grupos.

Observa-se na Figura 10 (Software) que, com relação aos subcritérios de tempo, o tempo de implementação foi considerado o mais importante quando comparado aos tempos de treinamento e produção, pelas duas amostras. Quanto aos subcritérios de funcionalidade, a adequação recebeu maior importância seguida da conformidade, customização, manutenibilidade e interoperabilidade. Já nos subcritérios de usabilidade, a facilidade de uso e eficiência tiveram pesos maiores que a criação de aplicações pelo usuário. Com relação aos subcritérios da flexibilidade, a escalabilidade ficou com o peso médio um pouco maior que os demais, facilidade de desenvolvimento in-house e portabilidade, assim como nos subcritérios de confiabilidade, a segurança se destacou com relação à recuperabilidade, maturidade e tolerância a falhas.

Observa-se na Figura 11 (Tecnológico) que, com relação aos subcritérios de Plataforma Tecnológica, a independência de plataforma foi considerada mais importante que a adequação da arquitetura técnica e linguagens e ferramentas de desenvolvimento, pelos dois grupos. Quanto aos subcritérios de serviços, 
o serviço de Internet se destacou em relação aos demais subcritérios de documentação do usuário e documentação técnica.
Na Figura 12 (Fornecedor) conclui-se que, com relação aos subcritérios do perfil do fornecedor, as referências foram consideradas mais importantes

Tabela 7. Comparação dos pesos médios entre os grupos de 79 e 32 respondentes.

\begin{tabular}{|c|c|c|c|c|}
\hline & & & Peso médio & Peso médio \\
\hline Atributo & Critérios & & 79 Resp. & 32 Resp. \\
\hline \multirow{8}{*}{ Financeiro } & \multirow{4}{*}{ Custo total } & Custo Inicial & 22,2 & 21,6 \\
\hline & & Custo de Implementação & 27,4 & 29,3 \\
\hline & & Custo de Treinamento & 21,6 & 18,6 \\
\hline & & Custo de Manutenção & 28,8 & 30,5 \\
\hline & \multirow{4}{*}{ Condições contratuais } & Condições comerciais & 23,8 & 21,8 \\
\hline & & Fornecimento de serviço & 24,0 & 23,4 \\
\hline & & Garantia & 26,8 & 27,0 \\
\hline & & SLA & 25,3 & 27,9 \\
\hline \multirow{4}{*}{ Negócio } & \multirow{4}{*}{ Estratégia } & Alinhamento com a estratégia de negócio & 37,6 & 39,5 \\
\hline & & Alinhamento com a estratégia de tecnologia & 25,3 & 25,5 \\
\hline & & Gerenciamento de mudanças & 20,0 & 19,5 \\
\hline & & Política de produção & 17,1 & 15,5 \\
\hline \multirow{18}{*}{ Software } & \multirow{3}{*}{ Tempo } & Tempo de Implementação & 41,4 & 46,2 \\
\hline & & Tempo de Treinamento & 29,5 & 26,7 \\
\hline & & Tempo de produção & 29,1 & 27,2 \\
\hline & \multirow{5}{*}{ Funcionalidade } & Adequação & 23,6 & 24,0 \\
\hline & & Interoperabilidade & 17,2 & 16,6 \\
\hline & & Conformidade & 20,0 & 20,8 \\
\hline & & Manutenibilidade & 18,9 & 18,2 \\
\hline & & Customização & 20,2 & 20,3 \\
\hline & \multirow{3}{*}{ Usabilidade } & Facilidade de uso & 38,6 & 37,7 \\
\hline & & Criação de aplicações pelo usuário & 26,7 & 25,5 \\
\hline & & Eficiência & 34,7 & 36,8 \\
\hline & \multirow{3}{*}{ Flexibilidade } & Facilidade desenvolv. in-house & 34,2 & 31,3 \\
\hline & & Escalabilidade & 35,6 & 38,5 \\
\hline & & Portabilidade & 30,2 & 30,2 \\
\hline & \multirow{4}{*}{ Confiabilidade } & Maturidade & 22,8 & 24,5 \\
\hline & & Tolerância a falhas & 22,4 & 22,7 \\
\hline & & Recuperabilidade & 23,3 & 23,2 \\
\hline & & Segurança & 31,5 & 29,7 \\
\hline \multirow{6}{*}{ Tecnológico } & \multirow{3}{*}{$\begin{array}{l}\text { Plataforma } \\
\text { Tecnológica }\end{array}$} & Independência de Plataforma & 37,8 & 41,0 \\
\hline & & Adequação da arquitetura técnica & 32,0 & 29,8 \\
\hline & & Linguagens e ferramentas de desenvolvimento & 30,2 & 29,2 \\
\hline & \multirow{3}{*}{ Serviços } & Serviço Internet & 38,3 & 40,0 \\
\hline & & Documentação do usuário & 31,4 & 31,0 \\
\hline & & Documentação técnica & 30,3 & 29,0 \\
\hline \multirow{9}{*}{ Fornecedor } & \multirow{3}{*}{ Perfil do Fornecedor } & Solidez financeira & 36,8 & 34,7 \\
\hline & & Referências & 37,3 & 40,9 \\
\hline & & Sustentabilidade e Responsabilidade Social & 25,9 & 24,4 \\
\hline & \multirow{3}{*}{ Capacidade técnica } & Disponibilidade de recursos & 33,0 & 35,2 \\
\hline & & Tecnologia P\&D & 30,7 & 29,2 \\
\hline & & Experiência do fornecedor & 36,3 & 35,6 \\
\hline & \multirow{3}{*}{ Suporte } & Serviço de suporte & 35,8 & 33,7 \\
\hline & & Relacionamento entre clientes e fornecedores & 30,1 & 30,5 \\
\hline & & Tempo de atendimento & 34,1 & 35,8 \\
\hline
\end{tabular}


Importância relativa aos critérios para seleção de Sistema ERP

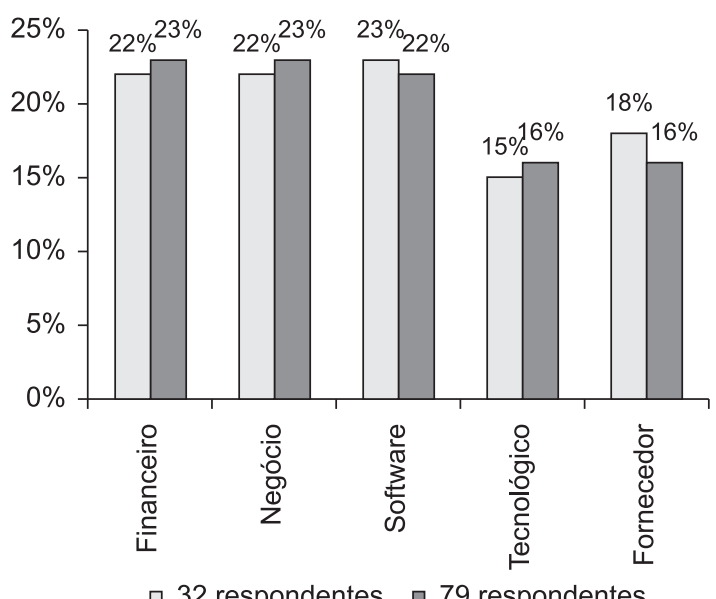

Figura 2. Critérios para Seleção de Sistema ERP para os grupos de 79 e 32 respondentes.

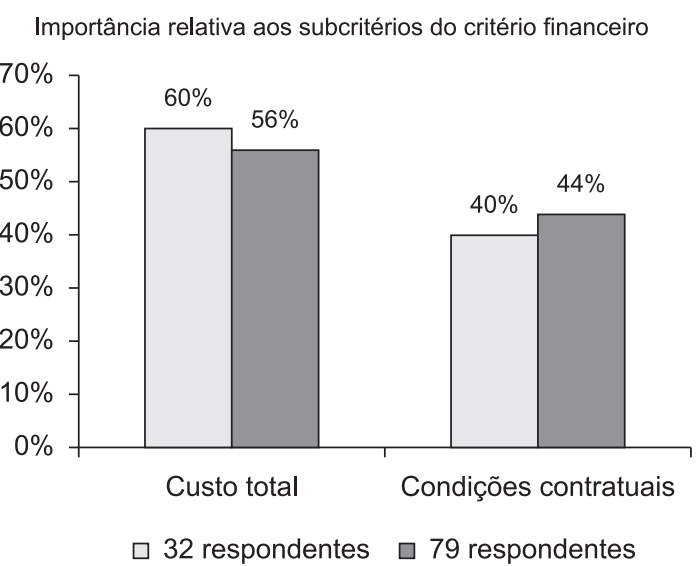

Figura 3. Critérios Financeiros para o grupo de 79 e 32 respondentes.

Importância relativa dos subcritérios do critério software

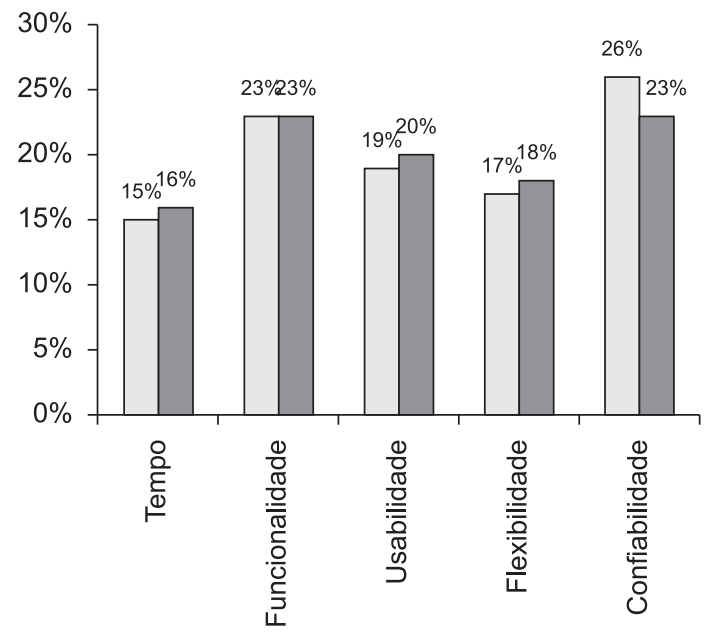

$\square 32$ respondentes $\square 79$ respondentes

Figura 4. Critérios de Software para o grupo de 79 e 32 respondentes.
Importância dos subcritérios

do critério tecnológico

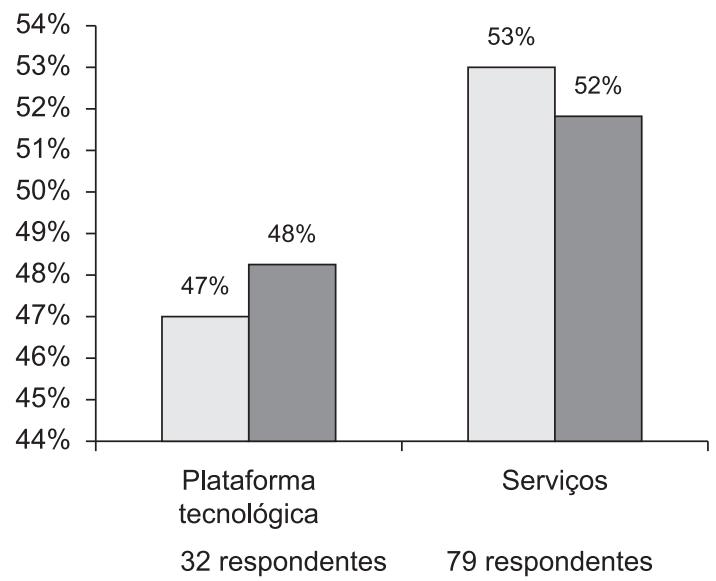

Figura 5. Critérios Tecnológicos para o grupo de 79 e 32 respondentes.

Importância relativa dos subcritérios
do critério fornecedor

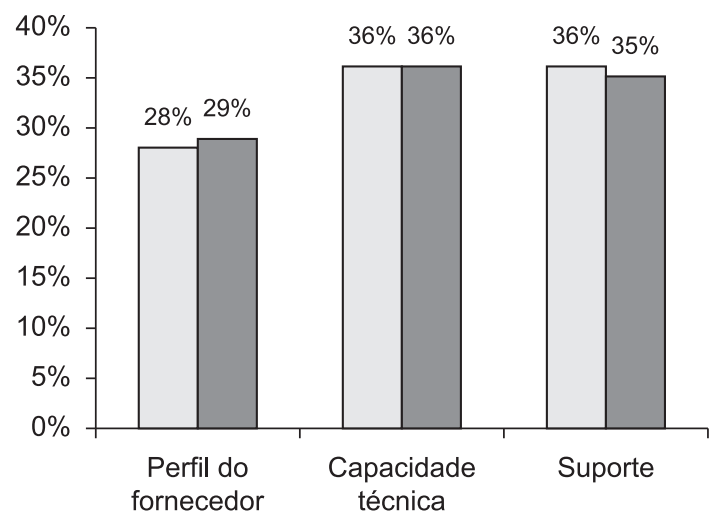

$\square 32$ respondentes $\square 79$ respondentes

Figura 6. Critérios do Fornecedor para o grupo de 79 e 32 respondentes.

seguidas da solidez financeira e sustentabilidade e responsabilidade social. Quanto aos subcritérios de capacidade técnica, a experiência do fornecedor obteve maior peso médio em relação à disponibilidade de recursos, seguida da tecnologia P\&D. Quanto aos subcritérios de suporte, o serviço de suporte está bem semelhante ao tempo de atendimento, seguido do relacionamento entre clientes e fornecedores.

Depois da análise comparativa apresentada nesta seção, observa-se que o grupo da segunda amostra, que são os 32 respondentes, apresentou um resultado muito semelhante ao grupo dos 79 respondentes, demonstrando afinidade nas respostas, mesmo pela parcela que não implementou sistemas ERP, que equivale a $60 \%$ da primeira amostra, ou seja, 47 respondentes. 


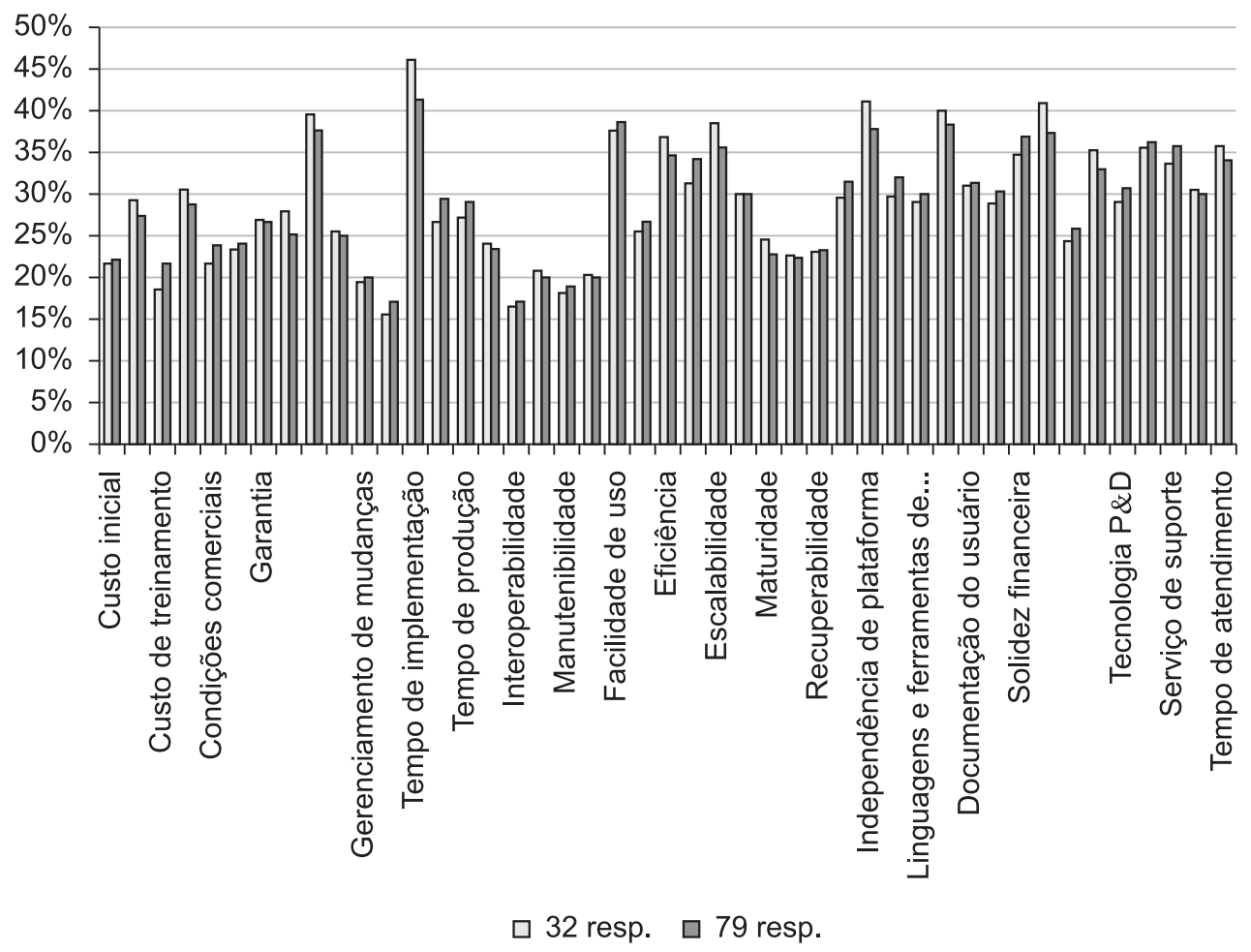

Figura 7. Distribuição de pesos pelos critérios do nível mais baixo da hierarquia.

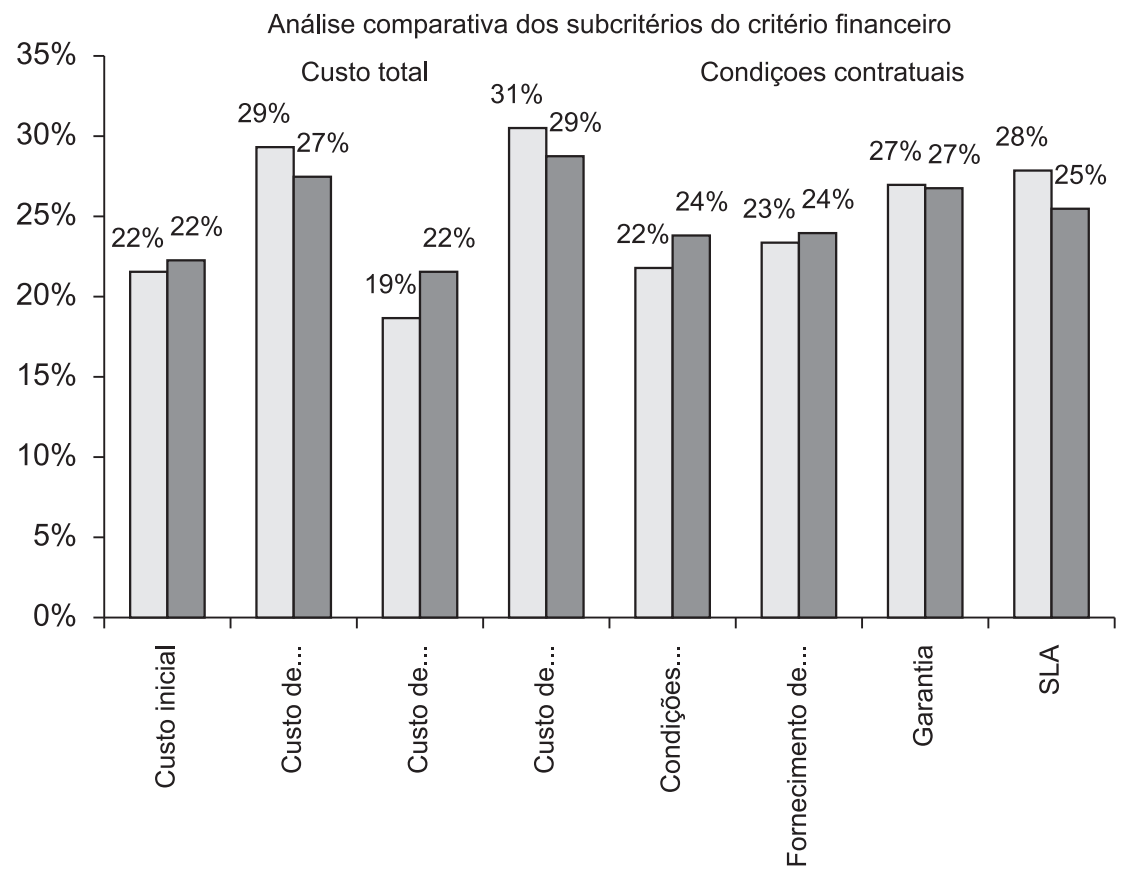

$\square 32$ resp. $\square 79$ resp.

Figura 8. Análise Comparativa dos Pesos Médios dos Subcritérios do Critério Financeiro. 
Análise comparativa dos subcritérios do critério negócio

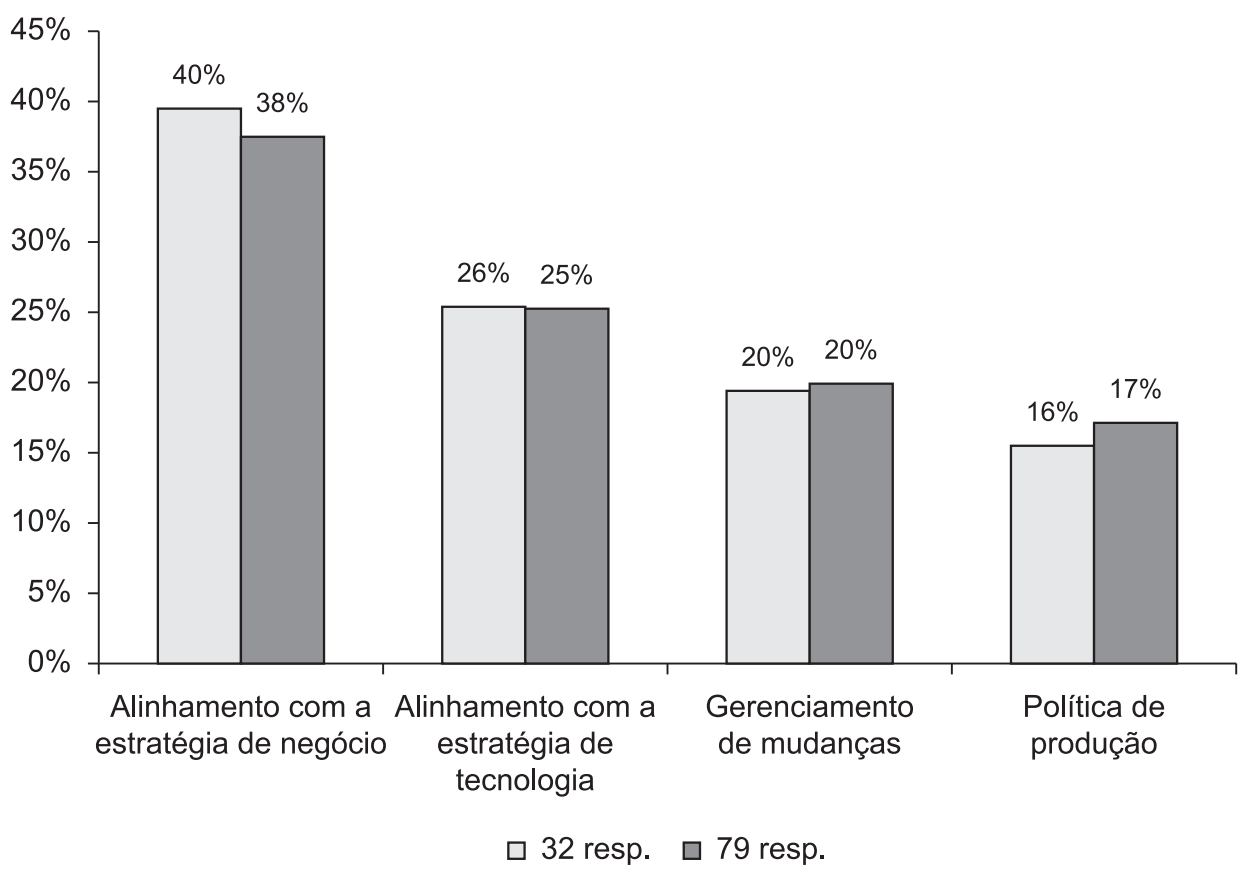

Figura 9. Análise Comparativa dos Pesos Médios dos Subcritérios do Critério Negócio.

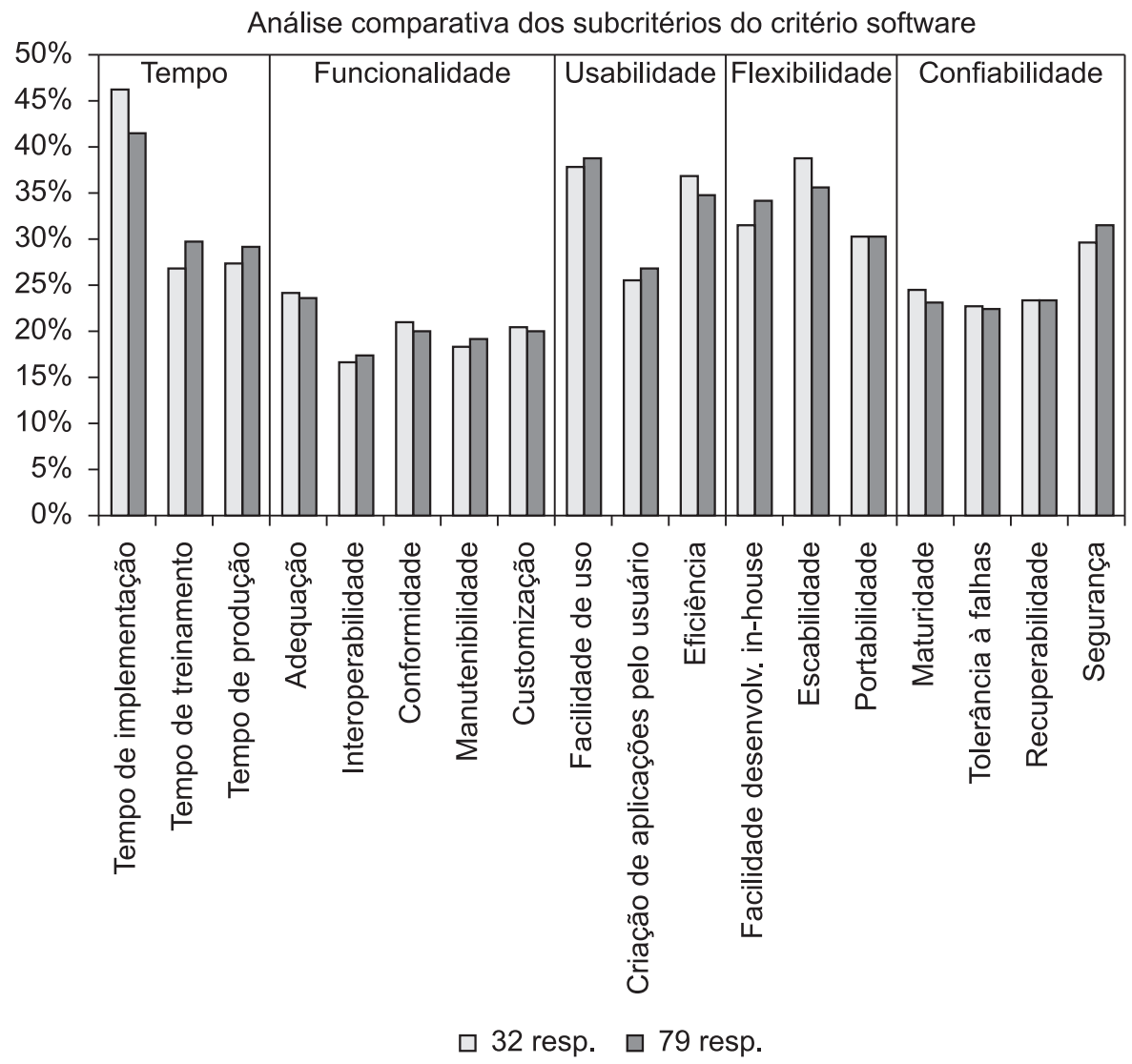

Figura 10. Análise Comparativa dos Pesos Médios dos Subcritérios do Critério Software. 
Análise comparativa dos subcritérios do critério tecnológico

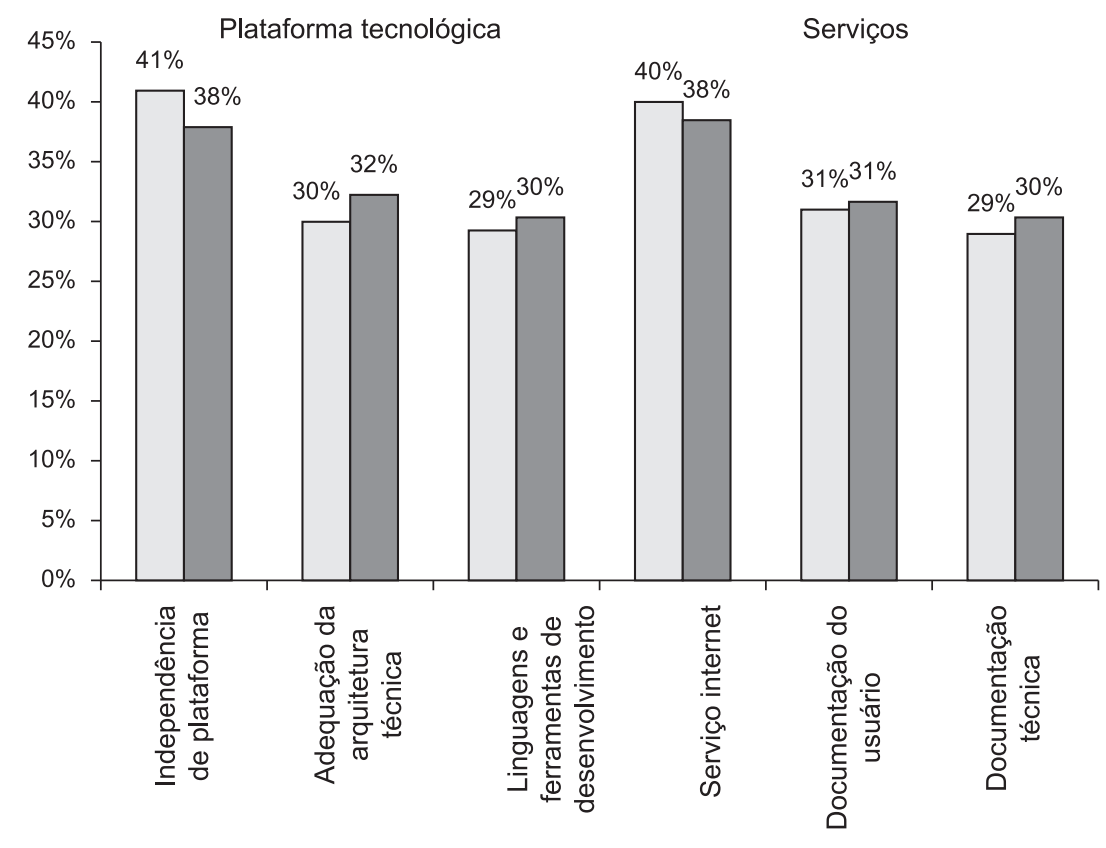

$\square 32$ resp. $\square 79$ resp.

Figura 11. Análise Comparativa dos Pesos Médios dos Subcritérios do Critério Tecnológico.

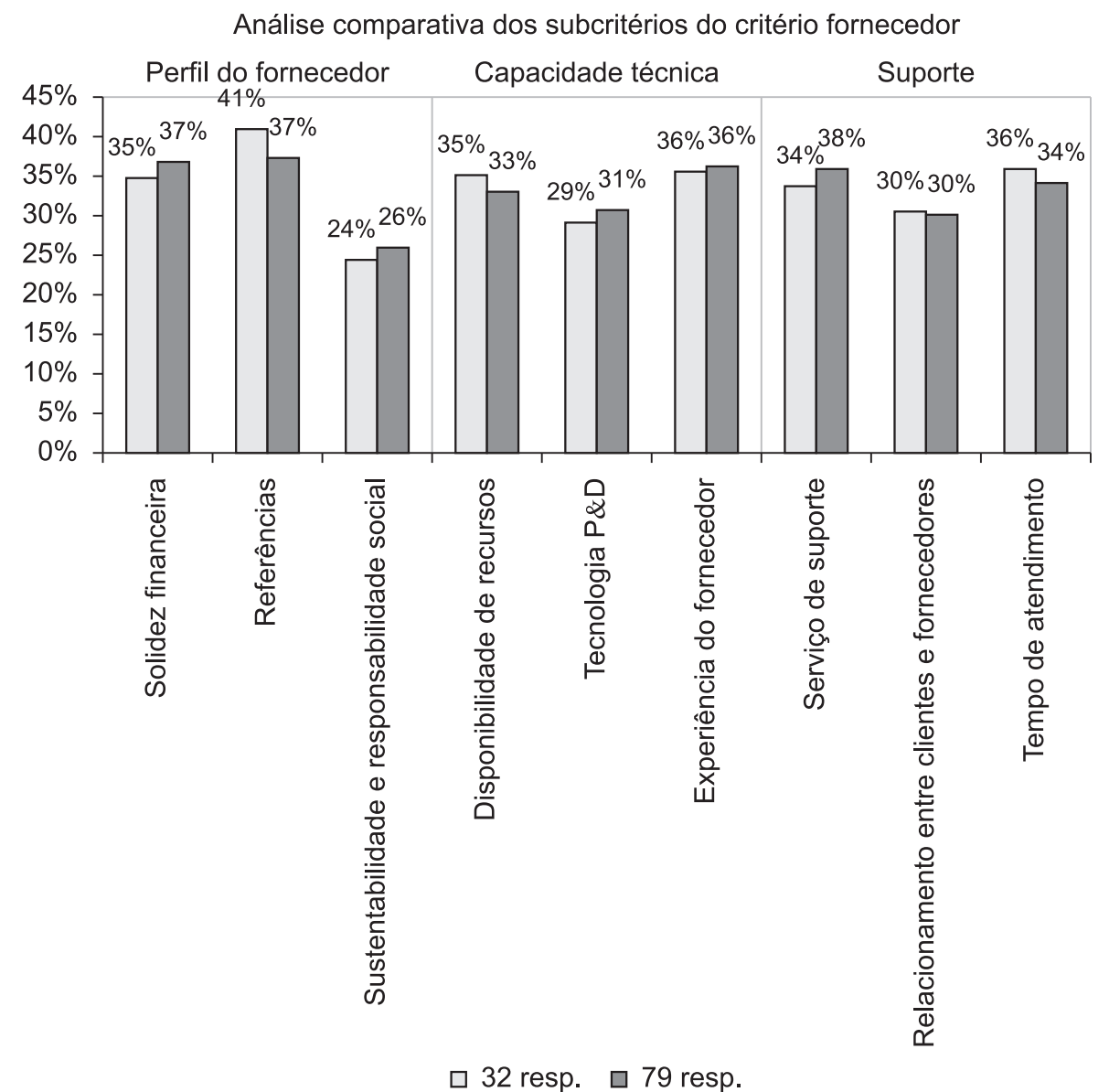

Figura 12. Análise Comparativa dos Pesos Médios dos Subcritérios do Critério Fornecedor. 


\section{Conclusão}

A revisão da literatura forneceu a base inicial para a proposta para modelagem aqui apresentada, a respeito da importância dos critérios e subcritérios para apoio à seleção de sistemas ERP para empresas da indústria da Construção Civil. Com base nesta revisão, foi elaborada uma estrutura com cinco grupos de critérios principais (Financeiro, Negócio, Software, Tecnológico e Fornecedor) e 45 subcritérios do nível mais baixo da hierarquia. Em diferentes momentos, esta estrutura foi validada por especialistas no tema em questão.

O mapeamento da percepção de especialistas a respeito da importância dos critérios e subcritérios para a seleção de sistemas ERP, foi feito por meio de uma pesquisa de campo, na qual foi aplicado um questionário a 79 respondentes. Durante o processo de análise, estas repostas foram organizadas em dois grupos: uma com 79 respondentes e outra com um subgrupo com 32 respondentes, os quais além de utilizarem sistemas ERP também trabalharam ou estiveram envolvidos com a implementação de sistemas integrados de gestão (ERP).

O questionário aplicado foi estruturado em duas seções: a primeira referente ao perfil de atuação do respondente. A segunda referente a priorizações dos critérios. O resultado do perfil dos profissionais entrevistados demonstra que a maioria dos respondentes das duas amostras trabalha em áreas de TI e Construção Civil, com predominância na área de TI, e possuem mais de 10 anos de experiência na área de atuação. Além disso, observa-se que a maioria dos respondentes utiliza P-ERP (ERP proprietário) em sua organização. Com relação ao envolvimento dos 79 respondentes na implementação de sistemas ERP, a maioria (60\%) não chegou a implementar.

O resultado da atribuição de pesos aos critérios do nível mais alto da hierarquia demonstrou que, para a amostra de 79 respondentes, os critérios Financeiro (24\%) e Negócio (23\%) foram considerados os mais importantes, seguidos do Software (21\%), Tecnológico (16\%) e Fornecedor (16\%). Já o grupo de 32 respondentes considerou o critério Software (23\%) o mais importante, seguido dos critérios Financeiro (22\%) e Negócio (22\%) e, depois, dos critérios Fornecedor (18\%) e Tecnológico (15\%). Isto se justifica pelo fato do segundo grupo estar mais focado na área de TI.

$\mathrm{O}$ resultado da atribuição de pesos aos critérios do segundo nível da hierarquia foi muito semelhante para as duas amostras, ou seja: para os subcritérios do Critério Financeiro, o custo total teve maior importância que as condições contratuais; para os subcritérios do Critério de Software, a confiabilidade e funcionalidade foram consideradas mais importantes; para os subcritérios do Critério Tecnológico, o subcritério serviços teve maior importância que a plataforma tecnológica; e para os subcritérios do Critério do Fornecedor, foi dada mais importância para a capacidade técnica.

$\mathrm{O}$ resultado da análise comparativa entre os resultados dos pesos médios atribuídos aos 45 subcritérios do nível mais baixo da hierarquia, pelas duas amostras, ficou também muito similar, demonstrando a afinidade nas respostas, mesmo pela parcela que não implementou sistemas ERP, que equivale a $60 \%$ da primeira amostra, ou seja, 47 respondentes. Os subcritérios que mais se destacaram foram: custo de manutenção, custo de implementação, SLA, garantia, alinhamento à estratégia de negócios, tempo de implementação, adequação, facilidade de uso, eficiência, escalabilidade, segurança, independência de plataforma, serviço de Internet, referências, experiência do fornecedor, serviço de suporte e tempo de atendimento. Observa-se que estes critérios não correspondem aos mais frequentemente adotados na literatura pesquisada, conforme destacado na seção 2 , embora tenham ocorrido algumas semelhanças.

Quanto à contribuição deste trabalho, espera-se que, por meio da utilização da estrutura proposta com o mapeamento da percepção de importância dos critérios, os gestores das empresas da indústria da Construção Civil possam tomar decisões mais precisas durante a seleção de sistemas ERP, por ser uma tendência do mercado a utilização de sistemas integrados de gestão. Além disso, a importância dos grupos de critérios e seus respectivos subcritérios poderá auxiliar não somente o tomador de decisão das empresas da construção civil, como também o fornecedor de software a ter maior conhecimento da importância dos subcritérios mais relevantes para a seleção de sistemas ERP, podendo dar mais foco a esses critérios quando for comercializar seu produto.

Como proposta para futuras pesquisas, sugere-se a utilização de coleta de julgamentos, objetivando especificamente a priorização dos critérios pelo método AHP e a comparação dos resultados aos obtidos na literatura. A indicação de se investigar a aplicação do AHP se deve ao fato deste ser o método AHP mais adotado para a seleção de sistemas ERP, conforme ficou demonstrado na revisão bibliográfica.

\section{Referências}

ASSOCIAÇÃO BRASILEIRA DE NORMAS TÉCNICAS - ABNT. ABNT NBR ISO/IEC 9126-1: Engenharia de software - Qualidade de produto. ABNT, 2003.

AYAG, Z.; OZDEMIR, R. G. An intelligent approach to ERP software selection through fuzzy ANP. International Journal of Production Research, v. 45, n. 10, p. 2169-2194, 2007. http://dx.doi. org/10.1080/00207540600724849 
BUENO, S.; SALMERON, J. L. Fuzzy modeling Enterprise Resource Planning tool selection. Computer Standards and Interfaces, v. 30, n. 3, p. 137-147, 2008. http:// dx.doi.org/10.1016/j.csi.2007.08.001

BUYUKOZKAN, G.; RUAN, D. Evaluation of software development projects using a fuzzy multi-criteria decision approach. Mathematics and Computers in Simulation, v. 77, n. 5-6, p. 464-475, 2008. http:// dx.doi.org/10.1016/j.matcom.2007.11.015

BYUN, D. H.; SUH, E. H. A methodology for evaluating EIS software packages. Journal of End User Computing, v. 8, n. 2, p. 21-31, 1996.

CARVALHO, R. A.; CAMPOS, R. Uma análise de aspectos relacionados ao desenvolvimento e adoção de Enterprise Resources Planning livre de código aberto. Gestão \& Produção, v. 16, n. 4, p. 667-678, 2009. http://dx.doi. org/10.1590/S0104-530X2009000400014

CARVALHO, R. A.; JOHANSSON, B. ERP Licensing Perspectives on Adoption of ERPs in Small and Medium-sized Enterprises. In: IFIP INTERNATIONAL CONFERENCE ON RESEARCH AND PRACTICAL ISSUES OF ENTERPRISE INFORMATION SYSTEMS, 2010, Natal. Proceedings... IFIP, 2010.

CHOUDHURY. Enterprise resource planning: A study of user satisfaction with reference to construction industry. In: ASEE ANNUAL CONFERENCE AND EXPOSITION CONFERENCE, 2009, Austin. Proceedings... ASEE, 2009.

EROL, I.; FERRELL JUNIOR, W. G. A methodology for selection problems with multiple, conflicting objectives and both qualitative and quantitative criteria. International Journal of Production Economics, v. 86, n. 3, p. 187-199, 2003. http://dx.doi.org/10.1016/ S0925-5273(03)00049-5

GHAPANCHI, A.; JAFARZADEH, M. H.; KHAKBAZ, M. H. Fuzzy-Data Envelopment Analysis approach to Enterprise Resource Planning system analysis and selection. International Journal of Information Systems and Change Management, v. 3, n. 2, p. 157-170, 2008. http://dx.doi.org/10.1504/IJISCM.2008.020693

$\mathrm{GOH}, \mathrm{B}$. H. Creating intelligent enterprises in the Singapore construction industry to support a knowledge economy. Building and Environment, v. 41, n. 3, p. 367-379, 2006. http://dx.doi.org/10.1016/j.buildenv.2005.01.021

KIM, J.; MOON, J. Y. An AHP and survey for selecting workflow management systems. International Journal of Intelligent Systems in Accounting, Finance, and Management, v. 6, n. 2, p. 141-161, 1997. http://dx.doi. org/10.1002/(SICI)1099-1174(199706)6:2<141::AIDISAF122>3.0.CO;2-2

LAUDON, J.; LAUDON, K. Management Information Systems. New Jersey: Prentice Hall, 2007.

LEE, H.; LEE, S.; PARK, Y. Selection of technology acquisition mode using the analytic network process. Mathematical and Computer Modelling, v. 49, n. 5-6, p. 1274-1282, 2009. http://dx.doi.org/10.1016/j. mcm.2008.08.010

LIN, H. Y.; HSU, P. Y.; SHEEN, G. J. A fuzzy-based decision-making procedure for data warehouse system selection. Expert Systems with Applications, v. 32, n. 3, p. 939-953, 2007. http://dx.doi.org/10.1016/j. eswa.2006.01.031

MARCONDES, F. C. S. Sistemas Logísticos Reversos na Indústria da Construção Civil: Estudo da Cadeia Produtiva de Chapas de Gesso Acartonado. 2007. Tese (Mestrado em Engenharia Civil em Engenharia Civil)-Escola Politécnica da Universidade de São Paulo, São Paulo, 2007.

NATALIA, C. et al. Model for the selection of ERP software: The Venezuelan case. Modelo para la selección de software ERP: El caso de Venezuela, v. 21, n. 1, p. 125-137, 2006.

NGAI, E. W. T.; WAT, F. K. T. A literature review and classification of electronic commerce research. Information \& Management, v. 29, p. 415-429, 2002. http://dx.doi.org/10.1016/S0378-7206(01)00107-0

NGAI, E. W. T.; XIU, L.; CHAU, D. C. K. Application of data mining techniques in customer relationship management: A literature review and classification. Expert Systems with Applications, v. 36, p. 25922602, 2009. http://dx.doi.org/10.1016/j.eswa.2008.02.021

NORD, J. H.; NORD, G. D. MIS Research: Journal status assessment and analysis. Information \& Management, v. 29, n. 29-42, 1995.

RODRIGUEZ, D. S. S.; COSTA, H. G.; DO CARMO, L. F. R. R. S. Análise multicritério aplicada à modelagem de problemas de PCP: Mapeamento da produção bibliográfica em periódicos publicados no Brasil. Gestão \& Produção, 2013. v. 20, n. 1, p. 134-146, 2013. http:// dx.doi.org/10.1590/S0104-530X2013000100010

ŞEN, C. G.; BARAÇLI, H. Fuzzy quality function deployment based methodology for acquiring enterprise software selection requirements. Expert Systems with Applications, v. 37, n. 4, p. 3415-3426, 2010. http:// dx.doi.org/10.1016/j.eswa.2009.10.006

ŞEN, C. G. et al. An integrated decision support system dealing with qualitative and quantitative objectives for enterprise software selection. Expert Systems with Applications, v. 36, n. 3 part 1, p. 5272-5283, 2009.

SHI, J. J.; HALPIN, D. W. Enterprise resource planning for construction business management. Journal of Construction Engineering and Management, v. 129, n. 2, p. 214-221, 2003. http://dx.doi.org/10.1061/ (ASCE)0733-9364(2003)129:2(214)

STAIR, R. M. Princípios de Sistemas de Informação: uma Abordagem Gerencial. São Paulo: Editora LTC, 1998.

TAVARES NETO, R. F.; GODINHO FILHO, M. Literature review regarding Ant Colony Optimization applied to scheduling problems: Guidelines for implementation and directions for future research. Engineering Applications of Artificial Intelligence, v. 26, n. 1, p. 150-161, 2013. http://dx.doi.org/10.1016/j.engappai.2012.03.011

TELTUMBDE, A. A framework for evaluating ERP projects. International Journal of Production Research, v. 38, n. 17 spec., p. 4507-4520, 2000.

VAN RAAN, A. F. J. The use of bibliometric analysis in research performance assessment and monitoring of interdisciplinary scientific developments. Technikfolgenabschätzung, Theorie und Praxis, v. 12, n. 1, p. 20-29, 2003. 
VLACHOPOULOU, M.; MANTHOU, V. Enterprise Resource Planning (ERP) in a construction company. International Journal of Business Information Systems, v. 1, n. 3, p. 339-351, 2006. http://dx.doi. org/10.1504/IJBIS.2006.008603

WEI, C.; WANG, M. A comprehensive framework for selecting an ERP system. International Journal of Project Management, v. 22, n. 2, p. 161-169, 2004. http://dx.doi.org/10.1016/S0263-7863(02)00064-9
WEI, C. C.; CHIEN, C. F.; WANG, M. J. J. An AHP-based approach to ERP system selection. International Journal of Production Economics, v. 96, n. 1, p. 47-62, 2005. http://dx.doi.org/10.1016/j.ijpe.2004.03.004

YAZGAN, H. R.; BORAN, S.; GOZTEPE, K. An ERP software selection process with using artificial neural network based on analytic network process approach. Expert Systems with Applications, v. 36, n. 5, p. 9214 9222, 2009. http://dx.doi.org/10.1016/j.eswa.2008.12.022 